\title{
Non-Invasive Determination Of the Location and Distribution of Free-Phase Dense Nonaqueous Phase Liquids (DNAPL) By Seismic Reflection Techniques
}

\section{Annual Technical Progress Report}

(October 1, 2000 - October 1, 2001)

$$
\text { by }
$$

Michael G. Waddell

William J. Domoracki

$\&$

Tom J. Temples

Earth Sciences and Resources Institute

University of South Carolina

Columbia, South Carolina

December 2001

DOE Award Number DE-AR26-98FT40369 
Disclaimer

This report was prepared as an account of work sponsored by an agency of the United States Government. Neither the United States Government nor any agency thereof, nor any of their employees, makes any warranty, express or implied, or assumes any legal liability or responsibility, for the accuracy, completeness, or usefulness of any information, apparatus, product, or process disclosed, or represents that its use would not infringe privately owned rights. Reference herein to any specific commercial product, process, or service by trade name, trademark, manufacturer, or otherwise does not necessarily constitute or imply its endorsement, recommendation, or favoring by the United States Government or any agency thereof. The views and opinions of authors expressed herein do not necessarily state or reflect those of the United States Government or any agency thereof. 


\begin{abstract}
This annual technical progress report is for part of Task 4 (site evaluation), Task 5 (2D seismic design, acquisition, and processing), and Task 6 (2D seismic reflection, interpretation, and AVO analysis) on DOE contact number DE-AR26-98FT40369. The project had planned one additional deployment to another site other than Savannah River Site (SRS) or DOE Hanford Site. After the SUBCON midyear review in Albuquerque, NM, it was decided that two additional deployments would be performed. The first deployment is to test the feasibility of using non-invasive seismic reflection and AVO analysis as a monitoring tool to assist in determining the effectiveness of Dynamic Underground Stripping (DUS) in removal of DNAPL. The second deployment is to the Department of Defense (DOD) Charleston Naval Weapons Station Solid Waste Management Unit 12 (SWMU-12), Charleston, SC to further test the technique to detect high concentrations of DNAPL.

The Charleston Naval Weapons Station SWMU-12 site was selected in consultation with National Energy Technology Laboratory (NETL) and DOD Naval Facilities Engineering Command Southern Division (NAVFAC) personnel. Based upon the review of existing data and due to the shallow target depth, the project team collected three Vertical Seismic Profiles (VSP) and an experimental P-wave seismic reflection line. After preliminary data analysis of the VSP data and the experimental reflection line data, it was decided to proceed with Task 5 and Task 6. Three high resolution P-wave reflection profiles were collected with two objectives; 1 ) design the reflection survey to image a target depth of 20 feet below land surface to assist in determining the geologic controls on the DNAPL plume geometry, and 2) apply AVO analysis to the seismic data to locate the zone of high concentration of DNAPL.

Based upon the results of the data processing and interpretation of the seismic data, the project team was able to map the channel that is controlling the DNAPL plume geometry. The AVO analysis located a major amplitude anomaly, which was tested using a Geoprobe ${ }^{\mathrm{TM}}$ direct push system. The Geoprobe ${ }^{\mathrm{TM}}$ was equipped with a membrane interface probe (MIP) that was interfaced with a sorbent trap/gas chromatograph (GC) system. Both the Photo Ionization Detector (PID) and Electron Capture Detector (ECD) on the GC exceeded the maximum measurement values through the anomaly. A well was installed to collect a water sample. The concentration of chlorinated solvents in the water sample was in excess of $500 \mathrm{ppm}$. Other amplitude anomalies located directly under an asphalt road were also tested. Both the PID and ECD were zero. It appears that editing of poor quality near-offset traces during data processing caused these anomalies. Not having the full range of source to receiver offset traces in those areas resulted in a false anomaly during AVO analysis. This phenomenon was also observed at the beginning and end of each seismic profile also for the same reason. Based upon the water samples and MIP probes, it appears that surface seismic and AVO analysis were able to detect the area of highest concentration of DNAPL.
\end{abstract}




\section{Table of Contents}

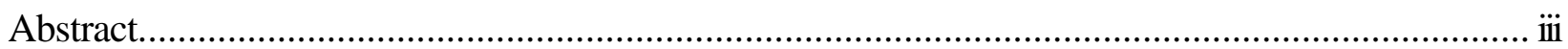

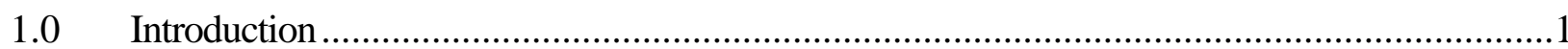

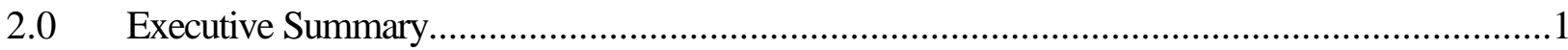

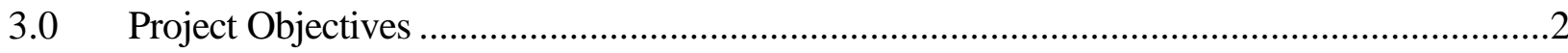

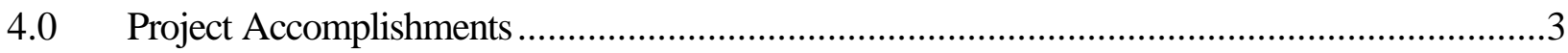

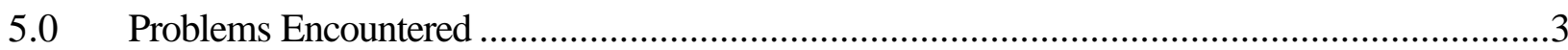

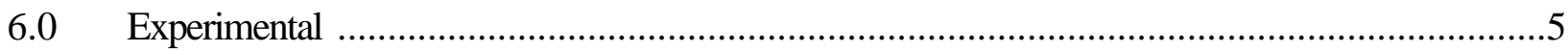

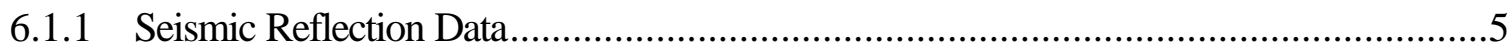

6.1.1 Vertical Seismic Profile (VSP) Data Acquisition .............................................5

6.1.2 Vertical Seismic Profile (VSP) Data Processing ......................................... 8

6.2 Amplitude Variation with Offset (AVO) Modeling...............................................18

6.3 Seismic Reflection Profiles.................................................................................19

6.3.1 Seismic Reflection Acquisition ..............................................................19

6.3.2 Seismic Reflection Data Processing........................................................21

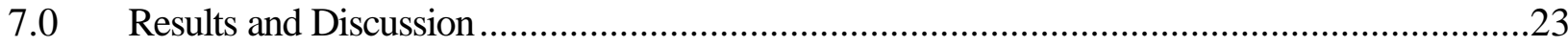

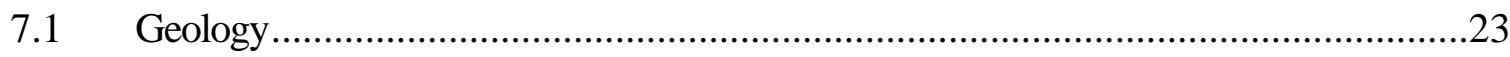

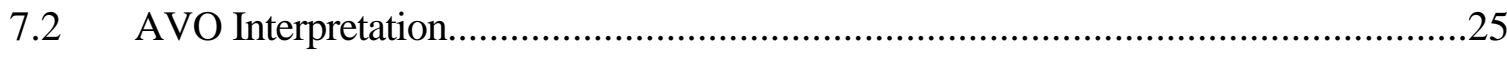

7.2.1 Seismic Profile CNWS-1 …..............................................................28

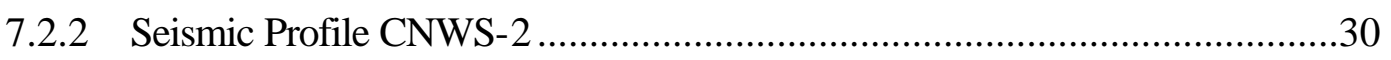

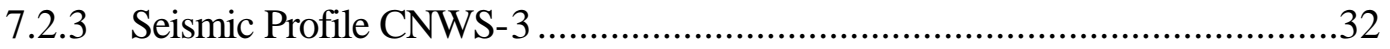

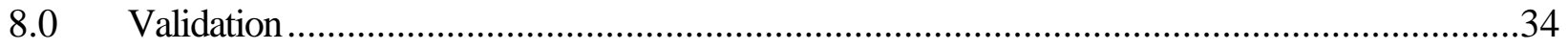

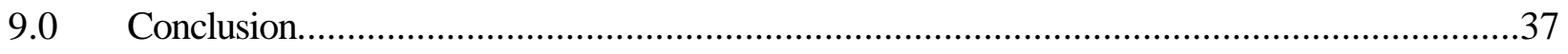

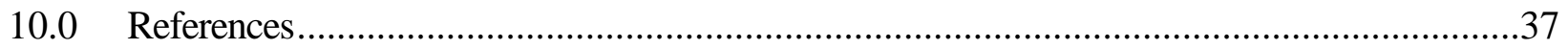




\section{List of Figures}

Figure 1. Location map of the wells and Seismic Lines at the SWMU-1 site. 4

Figure 2. Concentration map of total chlorinated solvents in the upper surficial aquifer at the SWMU-1 site. .5

Figure 3. VSP data processing flow. .9

Figure 4. Graph of $\mathrm{P}$ wave interval velocity, smoothed interval velocity, and average velocity versus depth in well 12MW-01D.

Figure 5. Graph of S wave interval velocity, smoothed interval velocity, and average velocity versus depth in well 12MW-01D.

Figure 6. Graph of $\mathrm{P}$ wave interval velocity, smoothed interval velocity, and average velocity versus depth in well 12MW05D

Figure 7. Graph of S wave interval velocity, smoothed interval velocity, and average velocity versus depth in well 12MW05D.

Figure 8. Amplitude Variation with Offset Models. .19

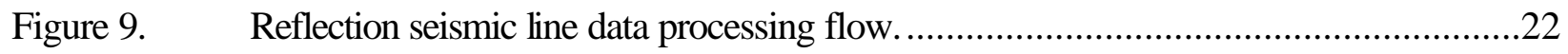

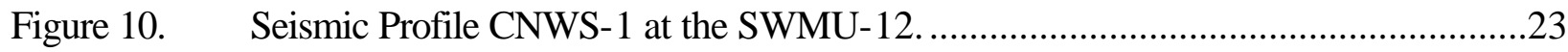

Figure 11. Seismic Profile CNWS-2 at the SWMU-12 …..............................................24

Figure 12. Seismic Profile CNWS-3 at the SWMU-12 ................................................25

Figure 13. Seismic Profile CNWS-1 AVO Gradient and Scaled Poisson's Ratio Stacks...........27

Figure 14. Seismic Profile CNWS-1 AVO Range Limited Stacks......................................29

Figure 15. Seismic Profile CNWS-2 AVO Gradient and Scaled Poisson's Ratio Stacks............31

Figure 16. Seismic Profile CNWS-3 AVO Gradient and Scaled Poisson's Ratio Stacks............33

Figure 17. Location map of the wells and MIP at the SWMU-1 site. ....................................34 
Figure 18. Air Photo of the SWMU-1 site showing water samples locations, selected MIP

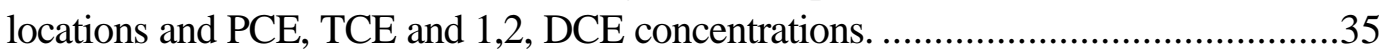

Figure 19. Air Photo of the SWMU-1 site showing water samples locations, selected MIP locations and TCA, and 1,1, DCE concentrations......................................................36 


\section{List of Tables}

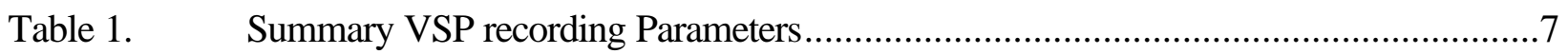

Table 2. P-wave velocity table from Well 12MW-01D......................................................10

Table 3. S-wave velocity table from Well 12MW-01D....................................................12

Table 4. P-wave velocity table from Well 12MW-05D........................................................14

Table 5. S-wave velocity table from Well 12MW-05D......................................................16

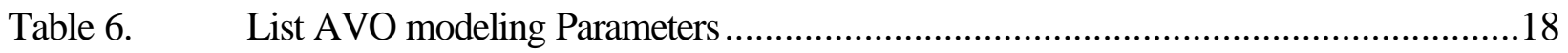

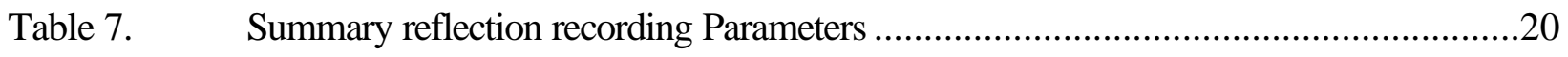

Table 8. Selected MIP locations for Validation and predicted results..........................................35 


\subsection{Introduction}

This annual technical progress report is the status of Task 4, 5, and 6 (site evaluation, 2D seismic design and acquisition, and interpretation) under DOE contact DE-AR2698FT40369. This report pertains to only Tasks 4, 5, and 6 at the Solid Waste Management Unit-12 (SWMU-12) at the Charleston Naval Weapons Station (Figure 1). This site offers some unique technical challenges in that the target depth for the seismic surveys is less than 20 feet below land surface. A second deployment of Tasks 5 and 6 was also to have been completed for this reporting period at the Dynamic Underground Stripping (DUS) site at Savannah River Site. However, the steam injection has not been completed; therefore we could not deploy and reshoot the seismic line DUS-1.

At the SWMU-12 site the greatest concentration of DNAPL is located in the upper 20 feet within the surficial aquifer (Figure 2)(Tetra Tech, NUS Inc, 2000). In the lower aquifer there appears to be very low concentrations of dissolved chlorinated solvents, so consequently the emphasis is to image the DNAPL in the upper surficial aquifer. Based upon review of existing data and due to the shallow target depth, the project team collected two Vertical Seismic Profiles (VSP) and an experimental p-wave seismic reflection line. After analysis of the VSP velocities and the processed experimental reflection line, it was decided to proceed with Task 5 (design, acquire, and process the 2D seismic data) and Task 6 (interpretation of the 2D reflection data). Three high-resolution reflection seismic profiles were acquired, processed, and interpreted. AVO analysis was applied to each seismic profile (Figure 1).

\subsection{Executive Summary}

This annual technical progress report is on Task 4 (site evaluation), Task 5 (design, acquire, and process the 2D seismic data), and Task 6 (interpretation and AVO analysis of the 2D reflection data) for Solid Waste Management Unit 12 (SWMU-12) at the Charleston Naval Weapons Station under DOE contact number DE-AR26-98FT40369. After the SUBCON midyear review in Albuquerque, NM (1999) and recommendations from the peer review, it was decided that two additional deployments would be performed on this project. The first deployment is to test the feasibility of using non-invasive seismic reflection and AVO analysis as a monitoring tool in determining the effectiveness of Dynamic Underground Stripping (DUS) in removal of DNAPL. The site selected for this feasibility study is the solvent storage area at Marea Savannah River Site. The second site is to test the concept under a differing set of geologic conditions.

The second deployment is to the DOD Charleston Naval Weapons Station, SWMU-12 site, Charleston, SC, which was selected in consultation with NETL and DOD NAVFAC Southern Division personnel. Tasks 4, 5, and 6 will be performed at the Charleston Naval Weapons Station. This site offers some unique technical challenges in that the target depth for the seismic data to image is very shallow, less than 20 feet below land surface.

At the SWMU-12 site the greatest concentration of DNAPL is located in the upper 20 feet within the surficial aquifer (Figure 2). In the lower aquifer there appears to be very low concentrations of dissolved chlorinated solvents, so therefore the emphasis is to image the 
DNAPL in the upper surficial aquifer. After review of existing data and considering the shallow target depth, the project team collected three Vertical Seismic Profiles (VSP) and an experimental reflection line. Analysis of the experimental reflection seismic profile suggested that there are reflections that can be imaged at the shallow depth where the DNAPL is occurring.

The next step was generating a series of reflection coefficient versus offsets (AVO) models to determine whether there will be a detectable change in seismic amplitude if DNAPL replaces water in the pore spaces. The results of the modeling suggested that there would be an amplitude anomaly if DNAPL replaced water in the pore spaces (Figure 8). The modeling results also indicated that more sophisticated AVO analysis would be required to detect DNAPL than using just range limited stacking techniques (employed at Savannah River Site) or enhancing the amplitudes looking for bright spots or dim-outs (employed at Hanford Site).

Three high-resolution P-wave reflection profiles were collected with two objectives; 1) design the reflection survey to image a target depth of 20 feet below land surface to assist in mapping the geologic conditions that control the DNAPL plume geometry, and 2) apply AVO analysis to the seismic data to locate the zone of high concentration of DNAPL (Figure 2).

Based upon the results of the data processing and interpretation of the seismic data, the project team was able to map the buried channel that is controlling the DNAPL plume geometry. The AVO analysis located a major amplitude anomaly that was tested using a Geoprobe $^{\mathrm{TM}}$ with a membrane interface probe (MIP) interfaced to a sorbent trap/GC system. When the MIP penetrated the AVO anomaly, both the Photo Ionization Detector (PID) and Electron Capture Detector (ECD) on the GC exceeded the maximum values throughout the anomaly. Subsequently, a well was installed to collect a water sample. The concentration of chlorinated solvents in the water sample was in excess of $500 \mathrm{ppm}$. Other amplitude anomalies were tested that were located directly under an asphalt road. In these cases both the PID and ECD were zero. Upon further examination of the unstacked data, it appears that the false AVO anomaly was caused the editing of poor quality near-offset data traces. The lack of full range of offsets in the CMP gather caused the amplitude anomaly. This phenomenon was also observed at the beginning and end of each seismic profile for similar reasons. Based upon the water samples and MIP probes, it appears that surface seismic and AVO analysis was able to detect the area of highest concentration of DNAPL.

\subsection{Project Objectives}

The research as initially proposed was a 14 month proof of concept study to determine the location and distribution of subsurface DNAPL contamination at the 200 West area, DOE Hanford Site by the use of two and three-dimensional high-resolution seismic reflection data and borehole geophysical surveys. The major change in the project objectives during this proof of concept phase is testing the feasibility of using this technique as a monitoring tool at the DUS project at the M-area solvent tanks area, Savannah River Site and at the Charleston Naval Weapons Station, Charleston SC. The specific objectives of the research at these sites are:

- Subsurface imaging of geologic sinks where DNAPL can pool. 
- Direct detection of DNAPL by use of seismic reflection amplitude versus offset (AVO) method in the very near surface.

- To test the feasibility of using high-resolution seismic techniques and AVO analysis as a monitoring tool in evaluating the effectiveness of the DUS technique at the Marea solvent tank area (SRS only).

\subsection{Project Accomplishments}

Tasks 4 and 5 have been completed for the SWMU-12 site at the Charleston Naval Weapons Station (CNWS). Task 6 is almost completed in that the structural interpretation, i.e. the geologic controls on the plume geometry, has been mapped on the seismic data. The initial AVO analysis has been completed and one major AVO anomaly appeared on the initial AVO analysis. This particular anomaly has been drilled with positive results. During this verification process the project team also drilled in areas that were absent of any AVO anomalies (nondetect). The project team also drilled some false anomalies that can be explained as data processing and acquisition artifacts. Now the project team is experimenting with several additional AVO analysis techniques used in the Petroleum industry to determine if these are applicable for detecting DNAPL.

\subsection{Problems Encountered}

According the milestone and status chart, the project team should have completed tasks 5 and 6 redeployment to the DUS site at Savannah River Site. Because the DUS process has been so successful in removing DNAPL from the subsurface, the steam injection and recovery has not been completed. The steam injection and recovery was scheduled to have ceased in May 2001, but at the end of this reporting period the steam injection and recovery is continuing. 


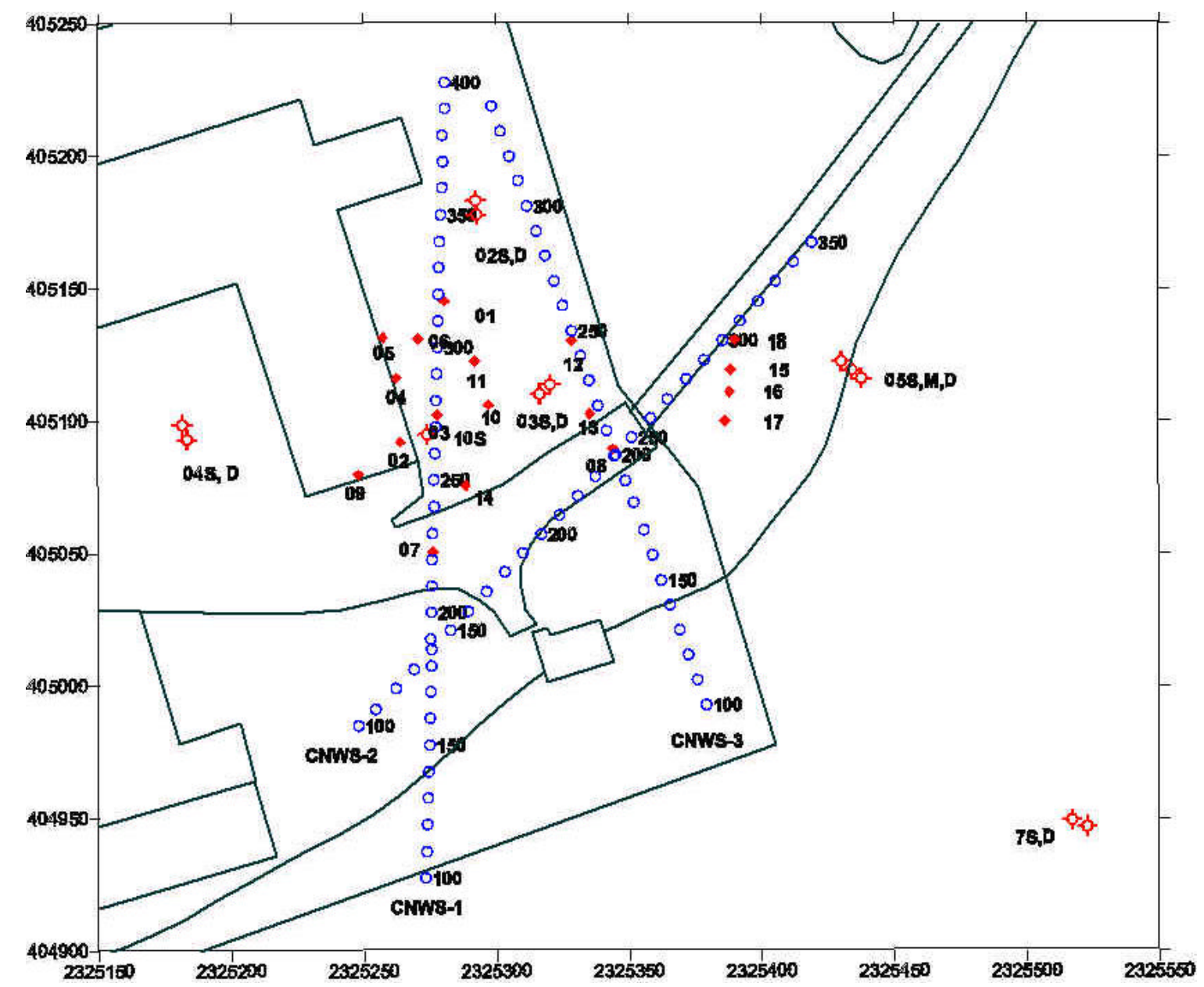

Figure 1. Location map of the Solid Waste Management Unit 12 (SWMU) site at the Charleston Naval Weapons Station. The blue circles are the location of every $50^{\text {th }}$ shot point. The circles with hash lines on the outside are well locations, the designation after the number indicates if the well is screened in the shallow zone (S) or the intermediate zone $(\mathrm{M})$ or the deep zone (D). The diamonds represent Membrane Interface Probe (MIP) locations. 


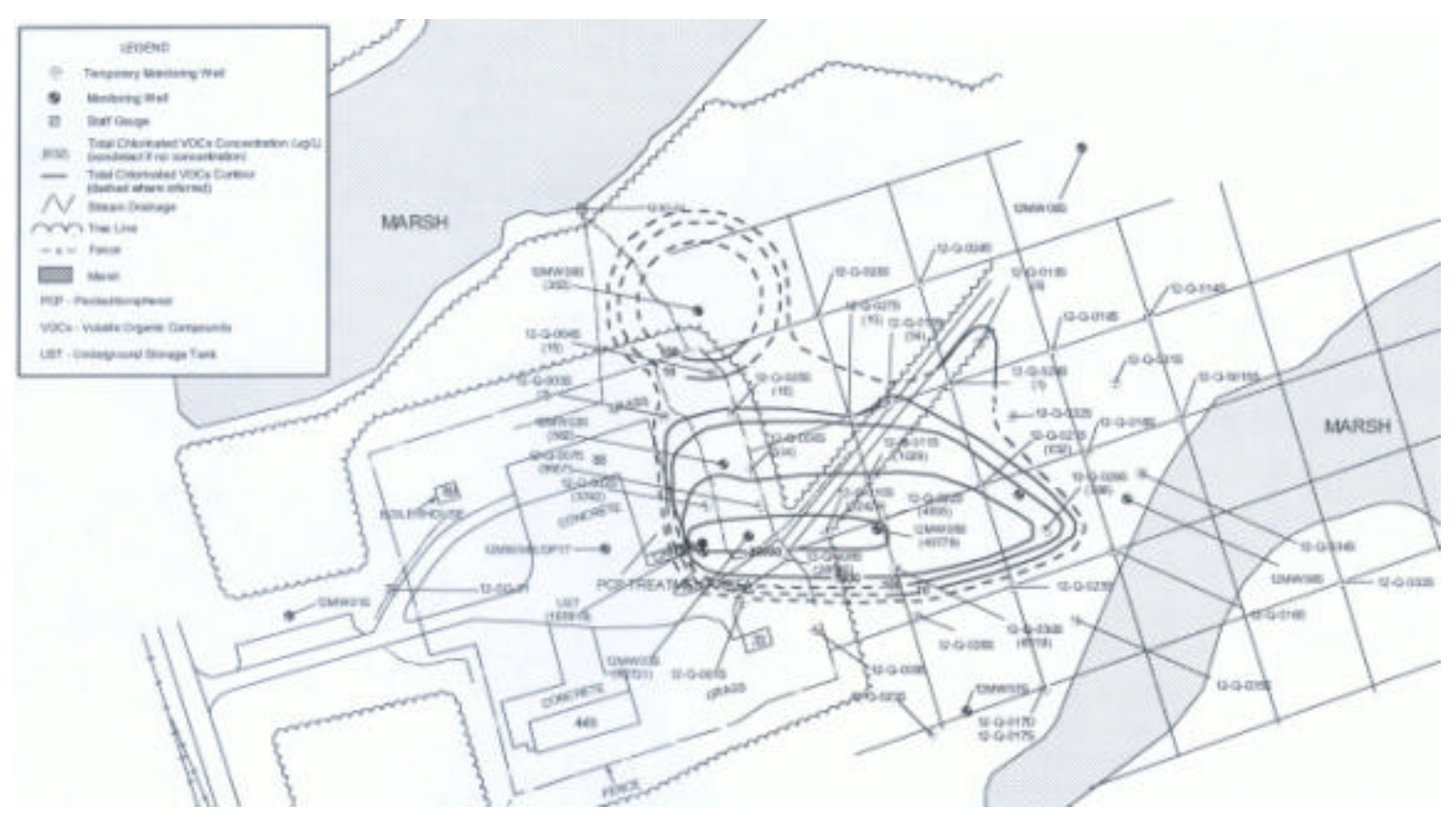

Figure 2. Contour map showing the total chlorinated solvent concentrations in the upper surficial aquifer at the SWMU-12 site. The outer dashed contour line is zero concentration and the inner contour line is 30,000 micrograms per liter.

\subsection{Experimental}

The Solid Waste Management Unit 12 (SWMU-12) at the Charleston Naval Weapons Station offers some unique technical problems for applying the AVO technique to directly detect DNAPL. The site is located in a low swampy area where the water table is almost at land surface. Based on results from both the Vertical Seismic Profiles (VSP) and a short experiment seismic reflection profile, it was determined by the project team that the shallow target could be imaged. The preliminary AVO models using velocities from the VSPs indicated that there would be an Amplitude Versus Offset anomaly (AVO) if Dense Non-Aqueous Phase Liquids (DNAPL) either completely or partially replaced the water within the pore spaces. Using the plume map (Figure 2) as a guide, three seismic profiles were located in such a manner so as to accomplish the two objectives (Figure 1).

\subsection{Seismic Reflection Data}

\subsubsection{Vertical Seismic Profile (VSP) Data Acquisition}

Vertical seismic profiles were collected in boreholes 12MW-01D, 12MW-05D, and 12MW-10S at the Charleston Naval Weapons Station (SWMU-12). These data include both 
compressional wave (P) (12MW-01D, 12MW-05D, 12MW-10S) and shear wave (S) (12MW-01D) recordings. The VSPs were collected to provide information on the subsurface $\mathrm{P}$ and S-wave velocity field of the geologic layers at and above the known DNAPL contamination at the Charleston Naval Weapons Station SWMU-12 (Figures 4-7). The velocity information was used to construct seismic models to investigate the probable amplitude versus offset (AVO) response that would be recorded by the surface seismic survey. In addition, the subsurface velocity information is needed to perform high-fidelity ties between the surface seismic profiles and the borehole lithology picks. The velocity versus depth information obtained from the VSPs can be used to convert interpretations made on the seismic data to depth.

Seismic recordings were made at 1 meter increments from the bottom of the borehole to approximately 1 meter below land surface using a three geophone (1 vertical, 2 horizontal) Geostuff sonde and an $8 \mathrm{lb}$. sledgehammer source. For P-wave acquisition a vertical steel cylinder was placed on the ground and struck four to eight times. Each hit was vertically summed to the preceding hits in the seismograph and written to disk as a single record for each level. For S-wave acquisition strike plates were mounted on the ends of an $8 \mathrm{ft}$ horizontal plank and a truck was driven on the plank to couple the plank to the ground. Each end of the plank was struck six to eight times, first from one side of the vehicle and then the other. The summed records for each source orientation were written to disk separately for each level.

Because of the relatively shallow depths of investigation and the critical need to have reliable subsurface velocity information, the P-wave VSPs from boreholes 12MW-01D, and 12MW-05D were logged multiple times with different seismographs and slightly different recording parameters. The recording parameters for each VSP are summarized in the Table 1. 
Table 1. Summary of VSP recording parameters.

\begin{tabular}{|c|c|c|c|c|}
\hline & 12MW-01D & 12MW-05D & 12MW-10S & 18CC-Q1 \\
\hline No. of VSP runs & $3 \mathrm{P}, 1 \mathrm{~S}$ & $2 \mathrm{P}, 0 \mathrm{~S}$ & $2 \mathrm{P}, 0 \mathrm{~S}$ & $3 \mathrm{P}, 1 \mathrm{~S}$ \\
\hline $\begin{array}{l}\text { Recorded depth } \mathrm{P} \text { wave } \\
\text { (m from TOC) }\end{array}$ & $1-12$ & $1-14$ & $1-5$ & $\begin{array}{l}1-31 \\
1-51,1-15\end{array}$ \\
\hline $\begin{array}{l}\text { Recorded depth S wave } \\
\text { (m from TOC) }\end{array}$ & $1-12$ & . & . & $1-31$ \\
\hline Source offset $\mathrm{P}$ wave $(\mathrm{m})$ & $\begin{array}{l}2.0-0.55,2.0- \\
0.55,2.0\end{array}$ & $2.0-0.55,2.0$ & $\begin{array}{l}0.55,1.0- \\
0.55\end{array}$ & $\begin{array}{l}2.5-1.5 \\
2.0,2.0\end{array}$ \\
\hline Source offset $\mathrm{S}$ wave $(\mathrm{m})$ & 1.82 & . & . & 2.5 \\
\hline No. of source hits P-wave & $4,8,8$ & 8 & 8 & 8 \\
\hline No. of source hits S-wave & $(6,6)$ & . & . & $(8,8)$ \\
\hline Depth increment $(\mathrm{m})$ & 1 & 1 & 1 & 1 \\
\hline Sample rate $\mathrm{P}$-wave (ms) & $\begin{array}{l}0.125,0.125, \\
.02833\end{array}$ & $0.125,0.021$ & $0.125,0.125$ & $\begin{array}{l}0.125,0.0283,0 . \\
02833\end{array}$ \\
\hline Sample rate S-wave (ms) & 0.125 &. &. & 0.125 \\
\hline Record length P-wave (ms) & 200 & 200 & 200 & 200 \\
\hline Record length S-wave (ms) & 200 & . & . & 400 \\
\hline Seismograph & $\begin{array}{l}\text { Seistronix } \\
\text { RAS-24 (P 1, } \\
2 \text { \& S) } \\
\text { Geometrics } \\
\text { Geode (P 3) }\end{array}$ & $\begin{array}{l}\text { Seistronix } \\
\text { RAS-24 (P 1) } \\
\text { Geometrics } \\
\text { Geode (P 2) }\end{array}$ & $\begin{array}{l}\text { Seistronix } \\
\text { RAS-24 }\end{array}$ & $\begin{array}{l}\text { Seistronix } \\
\text { RAS-24 (P } 1 \text { \& } \\
\text { S) } \\
\text { Geometrics } \\
\text { Geode (P 2, 3) }\end{array}$ \\
\hline
\end{tabular}




\subsubsection{Vertical Seismic Profile (VSP) Data Processing}

The generalized data processing flow for the VSP data appears below (Figure 3). The PC-based VISTA seismic processing software (Seismic Image Software, Ltd.) was used to process the data. In the field some rudimentary data processing was performed for QA/QC purposes using VISTA. The field QA/QC ensured that usable data were recorded. The field data processing also revealed that no usable VSP data could be obtained from borehole 12MW-10S.

First arrival times were picked on the P-wave records and the better of the two channels on the S-wave records. These times were corrected for source offset from the borehole to true vertical travel time (TVT), or zero-offset time, using a straight raypath assumption. No correction for reflection normal moveout was made. The velocity profile, average velocity and interval velocity, for each borehole was computed (Figures 4 through 7) using the data presented in Tables 2 through 5 . The average velocity (total depth divided by total time) from the surface to the recording depth is used to convert recording time to depth. The interval velocity, or velocity of the material between recording levels, is an approximate indicator of lithologic changes in the borehole.

For correlation to the surface seismic data displays of the up-going wavefield data were shifted to two-way reflection time (twice TVT) and narrow (3-10 trace) front corridor stacks were produced. Because the time-depth relationship for the front corridor stack is known, the depth to the reflectors in the subsurface can be found.

On the following pages appear the data tables and interval velocity curves from the best VSP profiles, P-wave and S-wave, recorded in boreholes 12MW-01D, 12MW-05D. Near the surface the pick times are unreliable because the seismic raypath is not favorably oriented with respect to the geophone. Thus, no velocity information is reported for the upper few meters of the borehole.

In borehole $12 \mathrm{MW}-05 \mathrm{D}$ it was possible to obtain $\mathrm{S}$-wave information by processing first arrival, information recorded on the shear wave geophones during the P-wave VSP. The $\mathrm{S}$-wave velocities found were compared to those obtained in 12MW-01D to verify that valid $\mathrm{S}$-wave velocities were computed. 


\section{Generalized Vertical Seismic Profile Data Processing Flow}

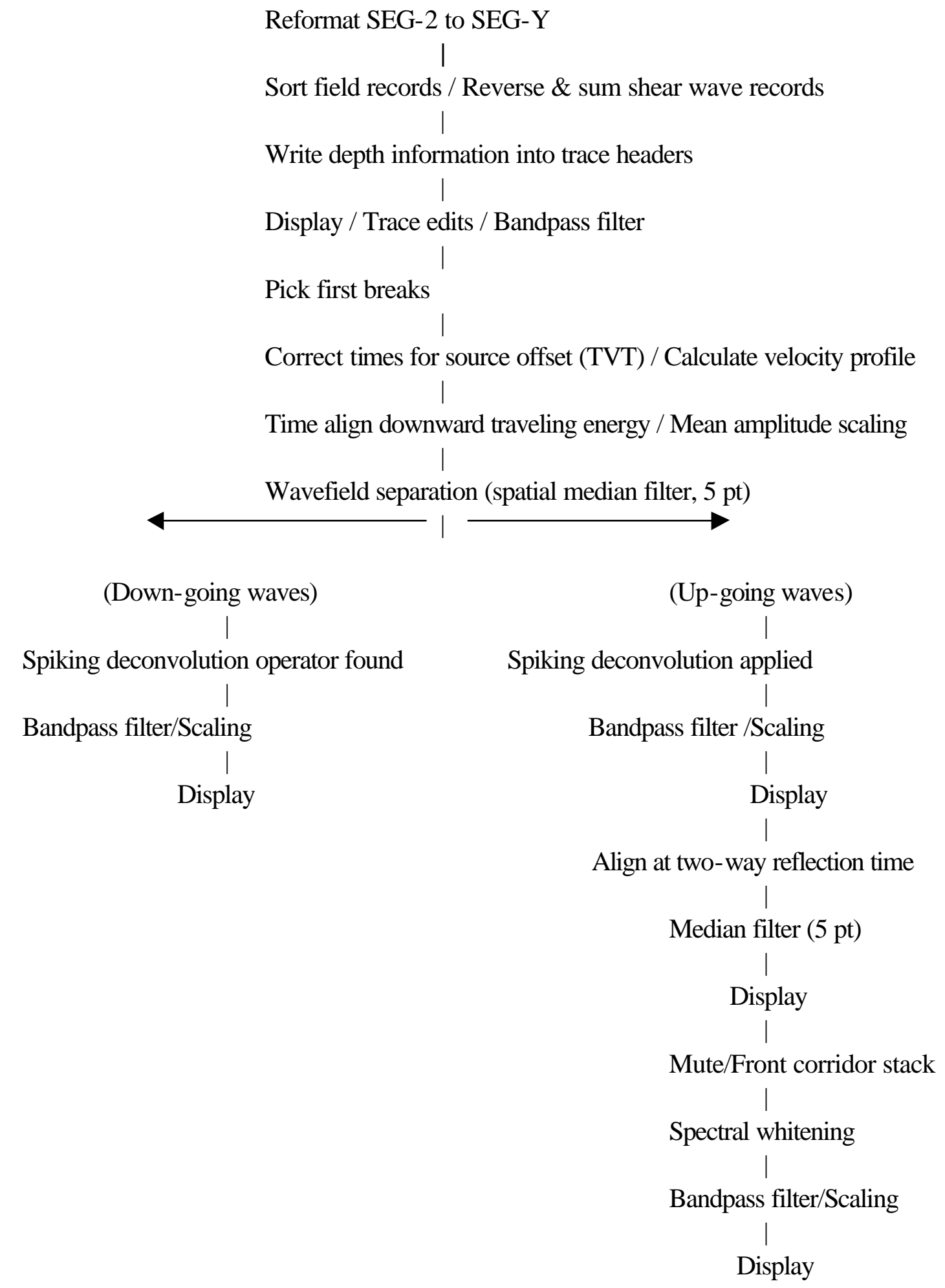

Figure 3. Vertical seismic profile (VSP) data processing flow. 
Table 2. P-wave velocity table from Well 12MW-01D

\section{Well 12MW-01D}

P-Wave Vertical Seismic Profile

$$
\begin{gathered}
\mathrm{GL}=2.52 \mathrm{~m} \quad \text { TOC }=.60 \mathrm{~m} \\
(\text { Offset }=2 \mathrm{~m})
\end{gathered}
$$

\begin{tabular}{|c|c|c|c|c|c|c|cc|}
\hline Seq. & $\begin{array}{c}\text { Depth } \\
(\text { TOC })\end{array}$ & Pick Time & $\begin{array}{c}\text { Depth } \\
(\mathrm{GL})\end{array}$ & $\begin{array}{c}\text { True } \\
\text { Vertical } \\
\text { Time } \\
(\mathrm{ms})\end{array}$ & $\begin{array}{c}\text { Average } \\
\text { Velocity }\end{array}$ & $\begin{array}{c}\text { Interval } \\
\text { Velocity }\end{array}$ & $\begin{array}{c}\text { Two-way } \\
\text { Time }\end{array}$ & $\begin{array}{c}\text { Gardner's } \\
\text { Density }\end{array}$ \\
No. & $(\mathrm{m})$ & $(\mathrm{ms})$ & $(\mathrm{m})$ & $(\mathrm{ft} / \mathrm{s})$ & $(\mathrm{ms})$ & $(\mathrm{g} / \mathrm{cc})$ \\
\hline 13 & 1 & 3.69 & 0.37 & 0.67 & 1808 & 1808 & 1.34 & 1.50 \\
12 & 2 & 4.00 & 1.37 & 2.26 & 1988 & 2064 & 4.52 & 1.55 \\
11 & 3 & 4.46 & 2.37 & 3.41 & 2281 & 2858 & 6.82 & 1.68 \\
10 & 4 & 4.65 & 3.37 & 4.00 & 2765 & 5558 & 8.00 & 1.99 \\
9 & 5 & 5.06 & 4.37 & 4.60 & 3116 & 5448 & 9.20 & 1.98 \\
8 & 6 & 5.98 & 5.37 & 5.60 & 3144 & 3271 & 11.21 & 1.74 \\
7 & 7 & 6.75 & 6.37 & 6.44 & 3245 & 3924 & 12.88 & 1.82 \\
6 & 8 & 8.40 & 7.37 & 8.11 & 2983 & 1968 & 16.21 & 1.53 \\
5 & 9 & 8.81 & 8.37 & 8.57 & 3205 & 7102 & 17.14 & 2.11 \\
4 & 10 & 9.25 & 9.37 & 9.05 & 3398 & 6872 & 18.09 & 2.09 \\
3 & 11 & 10.06 & 10.37 & 9.88 & 3444 & 3945 & 19.76 & 1.82 \\
2 & 12 & 10.33 & 11.37 & 10.17 & 3667 & 11090 & 20.35 & 2.36 \\
\hline
\end{tabular}




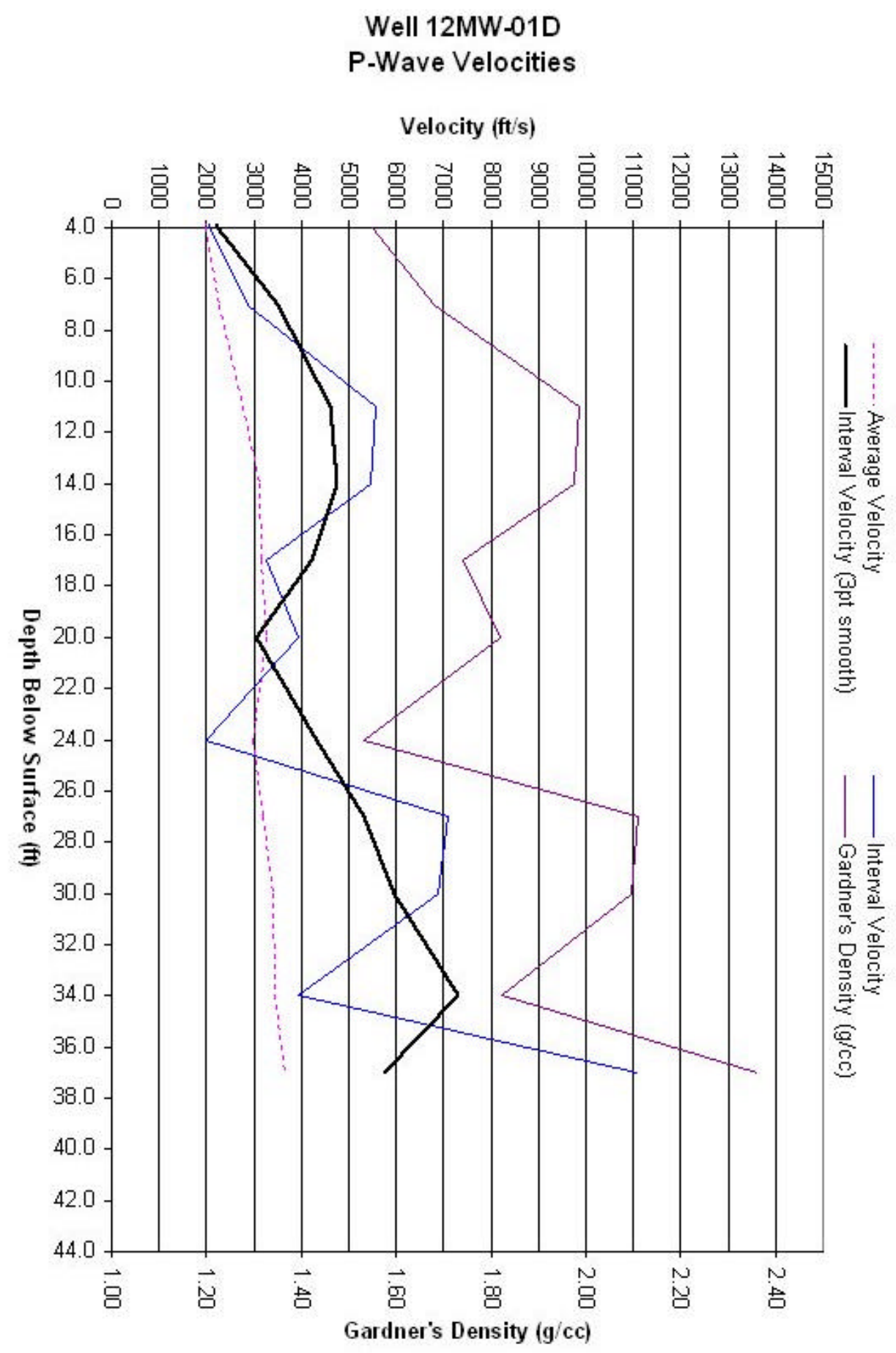

Figure 4. Graph of P-wave interval velocity, smoothed interval velocity, average velocity and Gardner's density derived from the p-wave velocity versus depth in borehole 12MW-01D. 
Table 3. S wave velocity table from well 12MW-01D

\section{Well 12MW-01D}

S-Wave Vertical Seismic Profile

GL $2.52 \mathrm{~m} \quad$ TOC $=0.6 \mathrm{~m}$

$($ Offset $=1.82 \mathrm{~m})$

\begin{tabular}{|c|c|c|c|c|c|c|c|}
\hline Seq. & $\begin{array}{c}\text { Depth } \\
\text { (TOC) } \\
(\mathrm{m}) \\
\end{array}$ & Pick Time & $\begin{array}{c}\text { Depth } \\
\text { (GL) } \\
\text { (m) } \\
\end{array}$ & $\begin{array}{c}\text { True } \\
\text { Vertical } \\
\text { Time } \\
(\mathrm{ms})\end{array}$ & $\begin{array}{c}\text { Average } \\
\text { Velocity } \\
(\mathrm{ft} / \mathrm{s})\end{array}$ & $\begin{array}{c}\text { Interval } \\
\text { Velocity } \\
(\mathrm{ft} / \mathrm{s})\end{array}$ & $\begin{array}{c}\text { Two-way } \\
\text { Time } \\
\text { (ms) }\end{array}$ \\
\hline 12 & 1 & 14.85 & 0.40 & 3.19 & 412 & 412 & 6.38 \\
\hline 11 & 2 & 15.00 & 1.40 & 9.15 & 502 & 551 & 18.29 \\
\hline 10 & 3 & 16.00 & 2.40 & 12.75 & 618 & 911 & 25.50 \\
\hline 9 & 4 & 20.50 & 3.40 & 18.07 & 617 & 616 & 36.15 \\
\hline 8 & 5 & 29.85 & 4.40 & 27.58 & 523 & 345 & 55.17 \\
\hline 7 & 6 & 37.25 & 5.40 & 35.30 & 502 & 425 & 70.60 \\
\hline 6 & 7 & 43.40 & 6.40 & 41.74 & 503 & 509 & 83.49 \\
\hline 5 & 8 & 49.90 & 7.40 & 48.46 & 501 & 489 & 96.91 \\
\hline 4 & 9 & 55.95 & 8.40 & 54.68 & 504 & 527 & 109.36 \\
\hline 3 & 10 & 61.40 & 9.40 & 60.28 & 512 & 586 & 120.56 \\
\hline 2 & 11 & 65.10 & 10.40 & 64.13 & 532 & 853 & 128.25 \\
\hline 1 & 12 & 70.35 & 11.40 & 69.47 & 538 & 614 & 138.94 \\
\hline
\end{tabular}




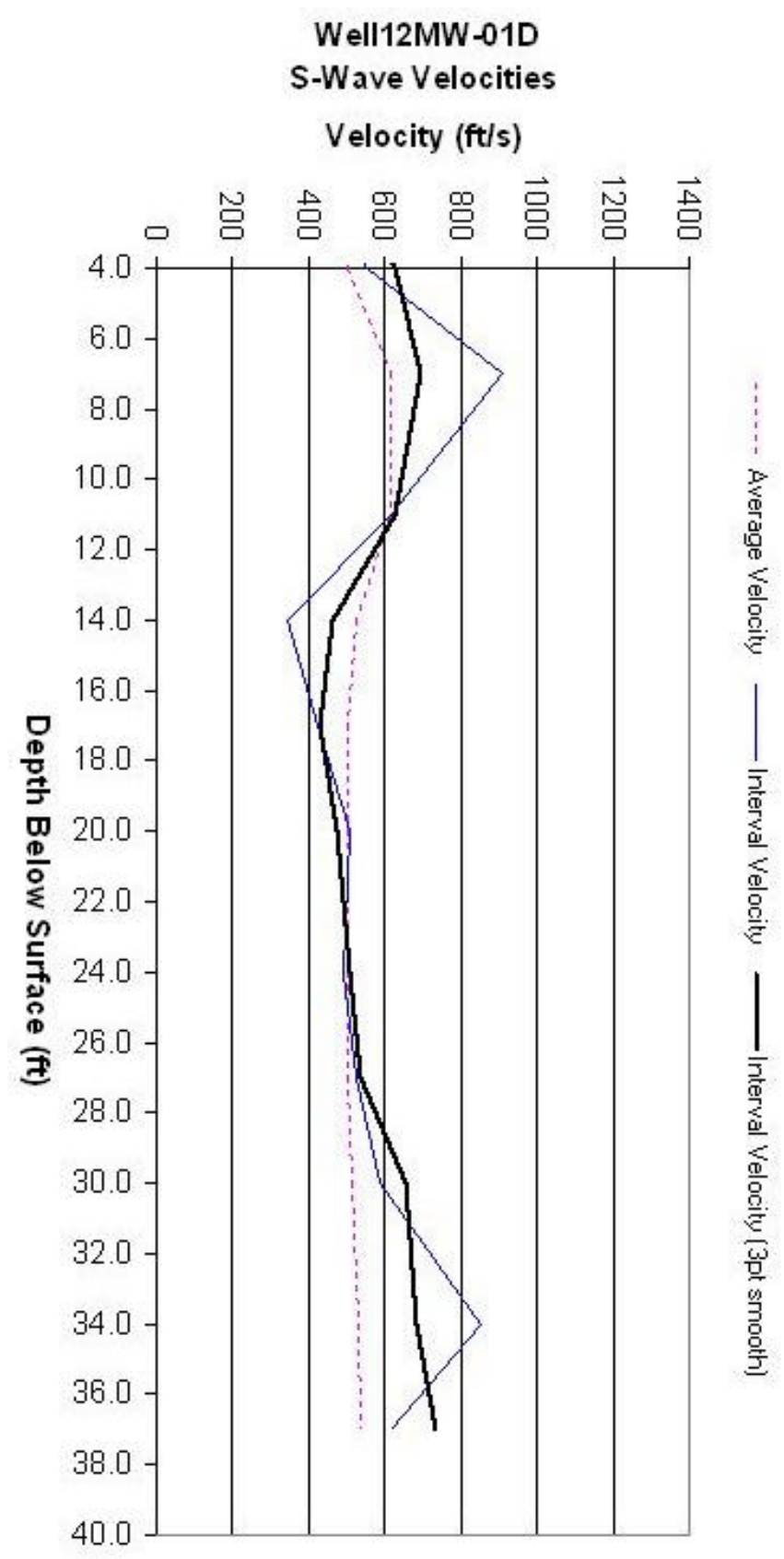

Figure 5. Graph of S-wave interval velocity, smoothed interval velocity and average velocity versus depth in borehole 12MW-01D. 
Table 4. P wave velocity table from well 12MW-05D

\section{Well 12MW-05D}

P-Wave Vertical Seismic Profile

$$
\mathrm{GL}=1.79 \mathrm{~m} \quad \mathrm{TOC}=0.43 \mathrm{~m}
$$

$($ Offset $=2 \mathrm{~m})$

\begin{tabular}{|c|c|c|c|c|c|c|c|}
\hline Seq. & $\begin{array}{c}\text { Depth } \\
\text { (TOC) }\end{array}$ & Pick Time & $\begin{array}{c}\text { Depth } \\
(\mathrm{GL})\end{array}$ & $\begin{array}{c}\text { True } \\
\text { Vertical } \\
\text { Time } \\
(\mathrm{ms})\end{array}$ & $\begin{array}{c}\text { Average } \\
\text { Velocity }\end{array}$ & $\begin{array}{c}\text { Interval } \\
\text { Velocity }\end{array}$ & $\begin{array}{c}\text { Two-way } \\
\text { Time }\end{array}$ \\
No. & $(\mathrm{ft})$ & $(\mathrm{ms})$ & $(\mathrm{m})$ & $(\mathrm{ft}) \mathrm{s})$ & $(\mathrm{ms})$ \\
\hline 10 & 5 & 8.750 & 4.57 & 8.02 & 1870 & 1870 & 16.03 \\
9 & 6 & 9.750 & 5.57 & 9.18 & 1991 & 2827 & 18.35 \\
8 & 7 & 10.250 & 6.57 & 9.81 & 2198 & 5213 & 19.61 \\
7 & 8 & 10.630 & 7.57 & 10.28 & 2417 & 6956 & 20.55 \\
6 & 9 & 11.500 & 8.57 & 11.20 & 2511 & 3559 & 22.40 \\
5 & 10 & 12.250 & 9.57 & 11.99 & 2618 & 4143 & 23.98 \\
4 & 11 & 13.130 & 10.57 & 12.90 & 2688 & 3605 & 25.80 \\
3 & 12 & 13.880 & 11.57 & 13.68 & 2775 & 4227 & 27.35 \\
2 & 13 & 14.630 & 12.57 & 14.45 & 2854 & 4255 & 28.90 \\
1 & 14 & 15.130 & 13.57 & 14.97 & 2974 & 6309 & 29.94 \\
\hline
\end{tabular}




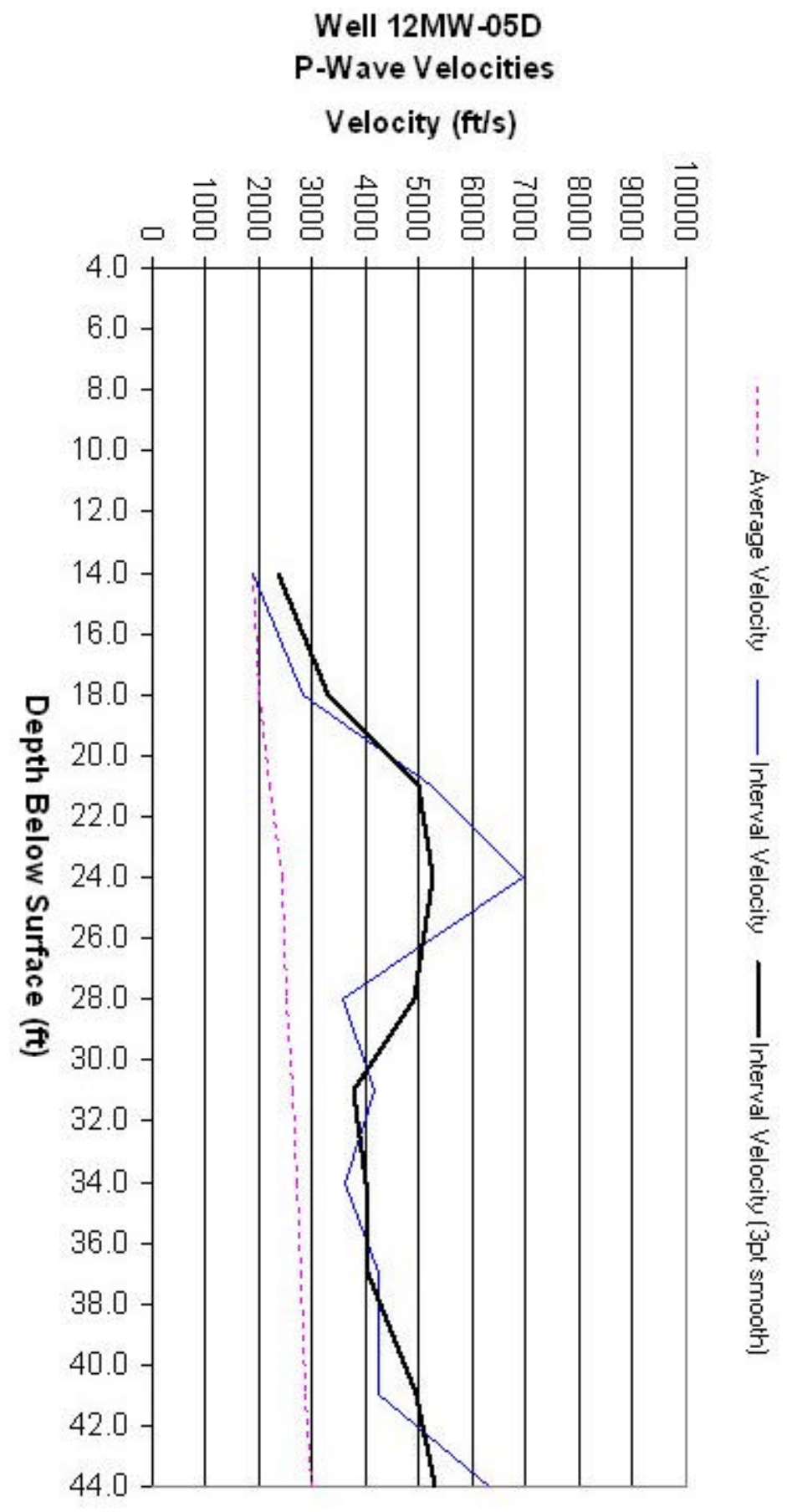

Figure 6. Graph of P-wave interval velocity, smoothed interval velocity and average velocity versus depth in borehole 12MW-05D. 
Table 5. S wave velocity table from well 12MW-05D

\section{Well 12MW-05D}

S-Wave Vertical Seismic Profile

$$
\begin{gathered}
\mathrm{GL}=1.795 \mathrm{~m} \quad \text { TOC }=0.43 \mathrm{~m} \\
(\text { Offset }=2 \mathrm{~m},(5-14 \mathrm{~m})) \\
(\text { Offset }=1 \mathrm{~m},(3-4 \mathrm{~m})) \\
(\text { Offset }=0.55 \mathrm{~m},(1-2 \mathrm{~m}))
\end{gathered}
$$

\begin{tabular}{|c|c|c|c|c|c|c|c|}
\hline Seq. & $\begin{array}{c}\text { Depth } \\
\text { (TOC) }\end{array}$ & Pick Time & $\begin{array}{c}\text { Depth } \\
(\mathrm{GL})\end{array}$ & $\begin{array}{c}\text { True } \\
\text { Vertical } \\
\text { Time } \\
(\mathrm{ms})\end{array}$ & $\begin{array}{c}\text { Average } \\
\text { Velocity }\end{array}$ & $\begin{array}{c}\text { Interval } \\
\text { Velocity }\end{array}$ & $\begin{array}{c}\text { Two-way } \\
\text { Time }\end{array}$ \\
No. & $(\mathrm{ft})$ & $(\mathrm{ms})$ & $(\mathrm{m})$ & $(\mathrm{ft} / \mathrm{s})$ & $(\mathrm{ms})$ \\
\hline 14 & 1 & 22.71 & 0.52 & 5.71 & 299 & 299 & 11.43 \\
13 & 2 & 20.31 & 1.52 & 12.29 & 406 & 499 & 24.58 \\
12 & 3 & 25.08 & 2.52 & 19.65 & 421 & 446 & 39.29 \\
11 & 4 & 29.99 & 3.52 & 26.08 & 443 & 510 & 52.17 \\
10 & 5 & 35.92 & 4.52 & 32.84 & 452 & 485 & 65.69 \\
9 & 6 & 46.10 & 5.52 & 43.35 & 418 & 312 & 86.69 \\
8 & 7 & 54.85 & 6.52 & 52.44 & 408 & 361 & 104.88 \\
7 & 8 & 63.27 & 7.52 & 61.14 & 404 & 377 & 122.29 \\
6 & 9 & 70.42 & 8.52 & 68.55 & 408 & 443 & 137.10 \\
5 & 10 & 75.04 & 9.52 & 73.44 & 425 & 672 & 146.87 \\
4 & 11 & 80.48 & 10.52 & 79.06 & 437 & 583 & 158.12 \\
3 & 12 & 86.42 & 11.52 & 85.14 & 444 & 540 & 170.28 \\
2 & 13 & 92.75 & 12.52 & 91.59 & 448 & 509 & 183.17 \\
1 & 14 & 97.48 & 13.52 & 96.43 & 460 & 678 & 192.86 \\
\hline
\end{tabular}




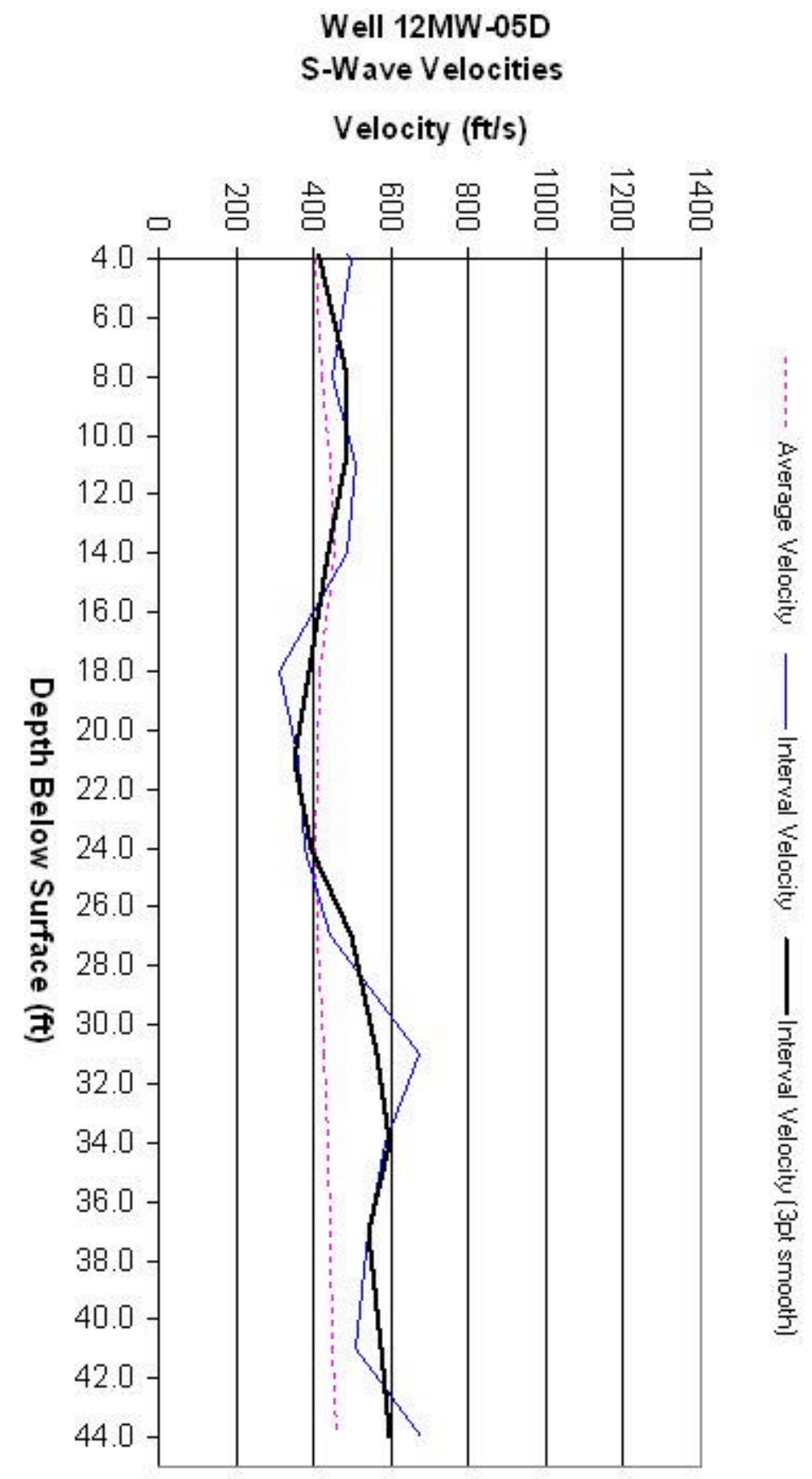

Figure 7. Graph of S-wave interval velocity, smoothed interval velocity and average velocity versus depth in borehole 12MW-05D. 


\subsection{Amplitude Variation with Offset (AVO) Modeling}

One of the most important aspects of AVO analysis to detect DNAPL is the AVO modeling. The modeling provides a guide as to whether the amplitude changes are the result of lithology change along a particular acoustic interface or the result of change in pore space fluid type. The modeling will determine the background seismic amplitude response along an interface and the expected change, if any, in the reflection amplitude if the fluid type or lithology changes along the interface.

The modeling conducted in this study is a two layer one-dimensional model of reflection coefficient versus incident angle. The P-wave reflection coefficients were calculated using the full Zoeppritz equations (1919) modified from Graul, 2001. The input into the Zoeppritz equations were P-wave and S-wave velocities calculated from the VSPs and modified using the Gassmann (1951) theory of fluid saturated rocks and densities derived from calculations using the empirical Gardner and others (1974) relationship between P-wave velocity and density.

Based upon existing geologic and concentration data (Tetra Tech NUS, 2000), the DNAPL is accumulating and confined to a sand layer (referred to as Unit 2) overlying a sandy clay unit (referred to as Unit 3). Using the physical parameters listed in Table 6 three scenarios were modeled (Figure 8). Fluid saturation in the pores is assumed to be 100 percent and porosity 35 percent.

The first scenario was to determine the background characteristic of the reflection coefficient versus offset if the pore spaces of both units are water filled (long dash line, Figure 8). The second scenario is to replace water in the pore spaces in the Unit 1 sand with DNAPL (solid line, Figure 8). The third scenario is to replace the water in the pore spaces in both units with DNAPL (short dash line, Figure 8).

It appears that if the pore spaces are water filled, the reflection coefficient is slightly negative until approximately $60^{\circ}$ degrees of offset where it becomes more negative (Figure 8). Based upon the two scenarios where DNAPL replaces water in the pore spaces there appears to be an AVO anomaly (Figure 8). Scenario one if DNAPL is present only in Unit 1 sand the reflection coefficient is slightly negative on the near offsets until approximately $30^{\circ}$ of incident angle at which point the reflection coefficient becomes positive. Scenario two if both the Unit 1 sand and the underlying Unit 2 sandy clay have DNAPL replacing water in the pore spaces the reflection coefficient begins negative well below that of the water filled case and becomes more negative at about $20^{\circ}$ of incident angle.

Table 6. List of parameters used in the AVO modeling.

\begin{tabular}{|l|c|c|c|}
\hline \multicolumn{1}{|c|}{ Lithology } & Density $(\mathrm{g} / \mathrm{cc})$ & P-Wave $(\mathrm{ft} / \mathrm{sec})$ & S-Wave $(\mathrm{ft} / \mathrm{sec})$ \\
\hline Unit 1 Sand & 1.99 & 5558 & 616 \\
\hline $\begin{array}{l}\text { Unit 1 Sand with } \\
\text { DNAPL }\end{array}$ & 2.36 & 4755 & 564 \\
\hline Unit 2 Sandy Clay & 1.98 & 5448 & 345 \\
\hline $\begin{array}{l}\text { Unit 2 Sandy Clay } \\
\text { with DNAPL }\end{array}$ & 2.36 & 4655 & 315 \\
\hline
\end{tabular}




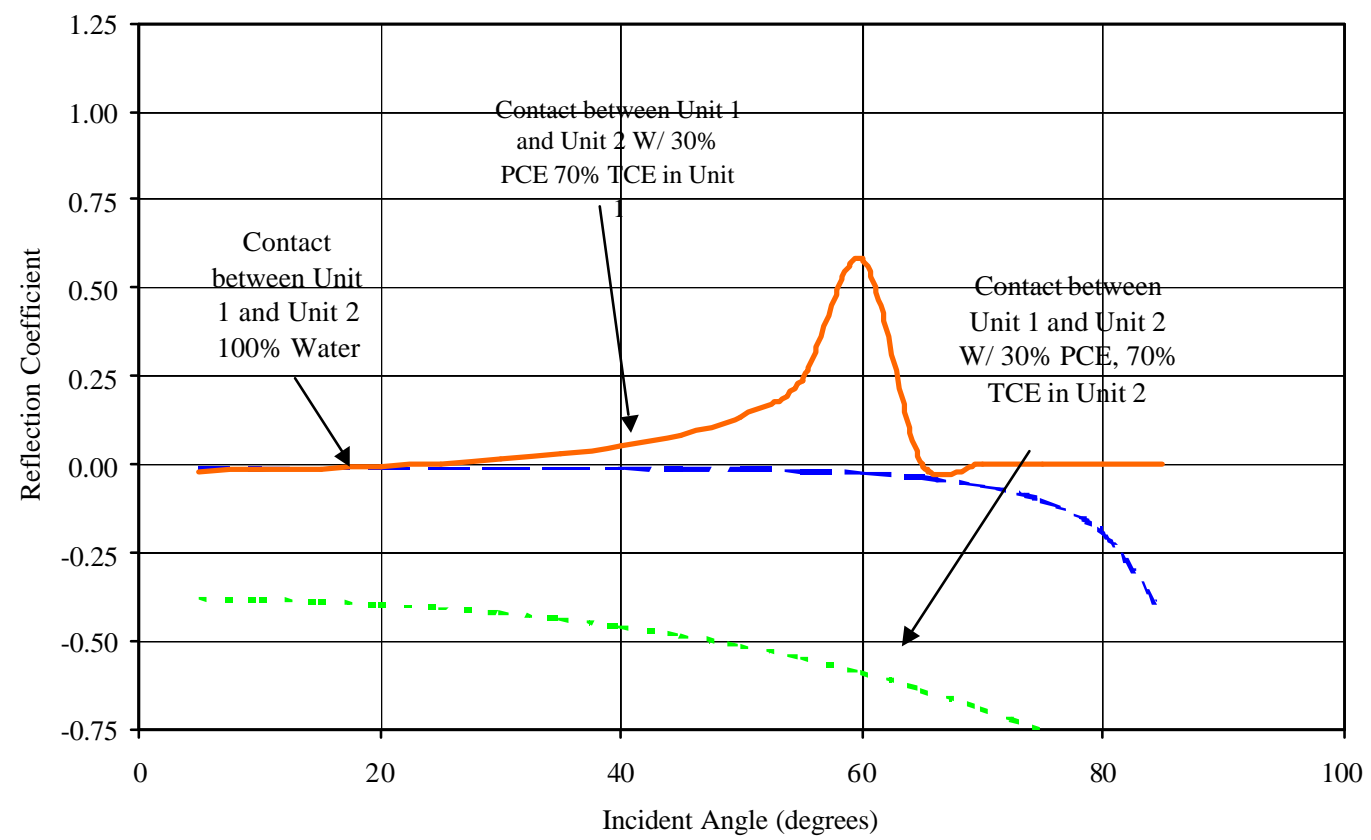

Figure 8. AVO models showing changes in reflection coefficients versus angle of offset using the full Zoeppritz equations.

\subsection{Seismic Reflection Profiles}

\subsubsection{Seismic Reflection Acquisition}

To evaluate the recording parameters needed to optimally image the target geologic horizons at the Charleston Naval Weapons Station SWMU-12, a test seismic reflection profile was recorded. Because target depths are shallow, 10-40 feet, adequate spatial sampling of the seismic wave field is critical. In addition, high frequency seismic wave energy must be generated and recorded to be able to resolve closely spaced reflectors.

The test line was recorded using a 24 channel recording system utilizing single $100 \mathrm{~Hz}$ geophones at two foot station spacing. The recording geometry was off-end with a 1 or 2 foot near offset. Source points were positioned at one foot station spacing on the half station so that tests could be done to process the data as either one foot or half foot CMP spacing to evaluate spatial resolution requirements. The line was first recorded using an $8 \mathrm{lb}$. sledgehammer source, then partly re-recorded using a $4 \mathrm{lb}$. sledgehammer source. This later test was done because a smaller seismic source can generate higher frequency waves needed for high resolution.

The results of the test profile indicated that quality seismic reflection data could be obtained from the target horizons. Ambient noise is not a problem, however, acoustic echoes were recorded off of buildings and infrastructure. Ground roll is a concern, but can be partly dealt with via two-dimensional filtering techniques. Furthermore, to adequately image the shallow reflectors of interest with sufficient subsurface redundancy for structural 
mapping and AVO analysis, source and receiver spacing of one foot are indicated. In addition, the smaller $4 \mathrm{lb}$. hammer yielded higher frequency data without loss of imaging the horizons of interest.

Based upon the results of the test profile and seismic AVO modeling, the parameters for acquisition of the production seismic lines were determined. The seismic lines were recorded using a 60 channel recording system utilizing single $100 \mathrm{~Hz}$ geophones at one foot station spacing. The recording geometry was off-end with 1.5 feet near offset and 60.5 feet far offset. Source points were positioned at one foot station spacing on the half station to yield nominal 30 CMP fold data. A $4 \mathrm{lb}$. Sledgehammer was used for a seismic source and six blows per source point were stacked and recorded. The parameters used to record the seismic data are listed in the table below.

Table 7. Seismic reflection profile recording parameters

\begin{tabular}{|l|l|}
\hline Type of survey & P-wave seismic reflection \\
\hline Station interval & 1 feet \\
\hline Source & 4 lb. Hammer, 6 hits per station \\
\hline \multicolumn{1}{|c|}{ Source interval } & 1 foot on half stations \\
\hline Record Length & 500 milliseconds \\
\hline Recording instrument & Geometrics Strataview 24 bit A/D res. \\
\hline Number of channels & 60 \\
\hline Instrument Gain & 24 dB fixed \\
\hline Sample interval & 0.25 millisecond \\
\hline Data format & SEG-2 \\
\hline Data redundancy & 30 fold max \\
\hline Geophones & Geospace $100 \mathrm{~Hz}$ vertical one per station \\
\hline \multicolumn{1}{|c|}{ Near offset } & 1.5 feet \\
\hline \multicolumn{1}{|c|}{ Far offset } & 60.5 feet \\
\hline Cable Geometry $(\mathrm{m})$ & SP------1.5'------60.5' \\
\hline
\end{tabular}




\subsubsection{Seismic Reflection Data Processing}

After completion of the field survey extensive detailed seismic data processing was performed at ESRI-USC's Environmental Geophysics Laboratory on the campus of the University of South Carolina. To process the data the Landmark Graphics Corp. state-of-theart ProMAX software operational on a Sun Microsystems Ultra-60 workstation was used. The generalized flow used to process the data is shown in Figure 9. Overall data quality is excellent with a dominant frequency of approximately $500 \mathrm{~Hz}$.

Two of the data processing steps deserve special mention. Although the water table is very shallow at the site, it was found that the near surface has considerable lateral velocity variation. Application of refraction statics was absolutely essential to account for the velocity variation. Without refraction statics it is doubtful whether the shallowest reflections would have stacked coherently and the stacked data overall would have had the high frequency content that it ultimately did.

The other data processing step that had significant impact on the data quality is the application of long-offset NMO corrections to the data. These corrections are not commonly applied to shallow data. The NMO correction commonly applied to seismic reflection data is derived from a two term mathematical formula that describes a hyperbolic travel-time curve. This correction is valid only for short offsets where the reflector depth is less than the source to receiver offset. In addition, there is an implicit assumption of an isotropic medium. At larger offsets and with the addition of anisotropy (multi-layering) the travel-time curve deviates from a hyperbola. In this case the application of conventional NMO corrections can lead to loss of effective fold (via larger mutes than necessary) and a degraded stack (less fold and incomplete moveout correction). The vast majority of seismic data are collected so that the "short offset" assumption is valid.

The seismic survey at CNWS recorded offsets to 60.5 feet. This maximum offset was need to record AVO responses. For reflections from reflectors shallower than 60.5 and particularly for those reflectors shallower than about 30 feet, the small offset assumption is not valid. Application of conventional NMO and stretch mute truncates the number of traces to be stacked in the CMP gather more than necessary.

Within the ProMAX software modules exist to apply "third-term" or "long-offset" NMO corrections. The method developed by Tsvankin and Thomsen (1994) was applied to the CNWS data set. The application of the long-offset NMO correction improved the imaging of shallow reflections occurring $20 \mathrm{~ms}$ and earlier. 


\section{Seismic Data Processing Flow}

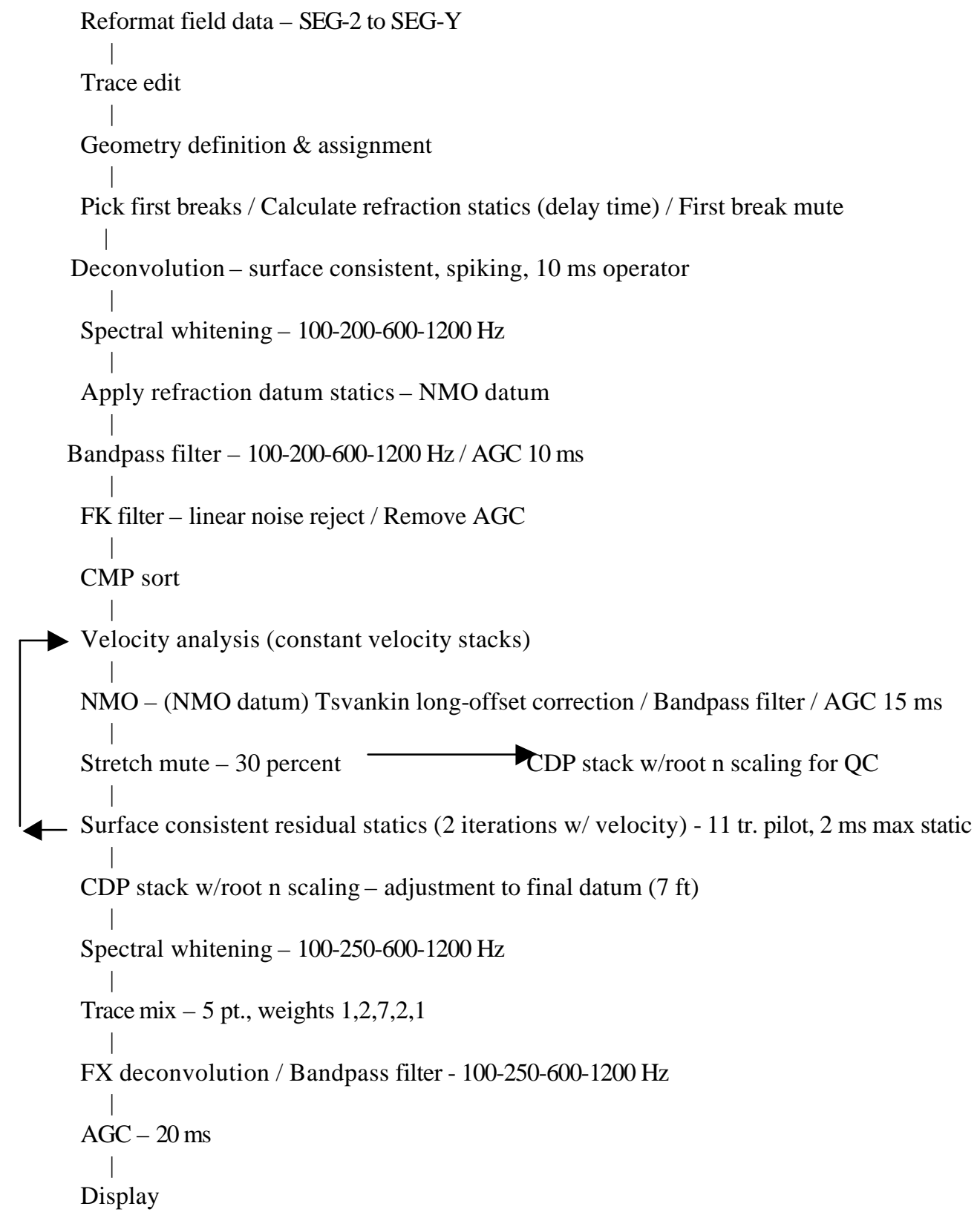

Figure 9. Diagram showing the data processing sequence followed to produce the seismic sections. 


\subsection{Results and Discussion}

The Navy had two dojectives for the project team, the first was to locate the high concentrations of DNAPL using non-intrusive seismic techniques and AVO analysis, and second to use the seismic data in conjunction with existing well data to determine the geologic controls on the plume geometry. Therefore, the first section will be on the geology and second part will be on the AVO analysis for DNAPL detection.

\subsection{Geology}

The project team was able to extract $500 \mathrm{~Hz}$ data from the shallow subsurface. This high frequency alows a vertical resolution of approximately 1.5 to 2 feet. The data has a subsurface horizontal resolution of 0.5 feet as a consequence of the one foot geophone spacing. With this high frequency data the project team was able to map not only the gross features such as lithologic boundaries and channels features, but features within the individual channels. In Figures 10 though 12 are seismic profiles CNWS-1, 2., and 3 plotted as amplitudes. On each of the seismic lines are two interpretation lines. The purple line is the base of an old channel or described as a channel scour and the green line is the base of a younger channel that has incised into the older channel. In Figure 10, (CNWS-1) it appears that the seismic profile crossed both channels almost perpendicular to the strike of the channel.

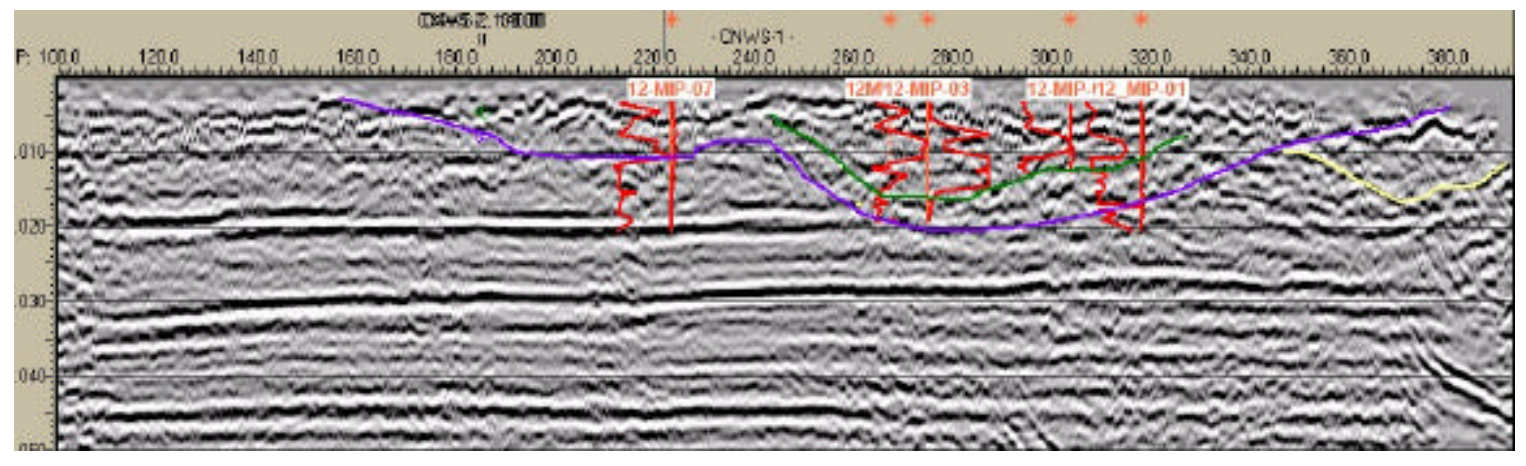

Figure 10. CNW1 seismic reflection profile, the purple line is interpreted at the major channel or the oldest, the green line is another channel within the older channel complex and the yellow line is yet another channel complex. The red line to the left of the vertical red line is a conductivity $\log$ and to the right is the ECD $\log$ for the Geophone ${ }^{\mathrm{TM}}$ MIP. On the conductivity $\log$ deflections to the right indicates conductive soil such as clays. The ECD log deflections to the right indicate an increase in compounds containing chlorine. The blocky pattern on the ECD indicates that the amount of chlorine compounds has exceeded the maximum resolution of the probe. 


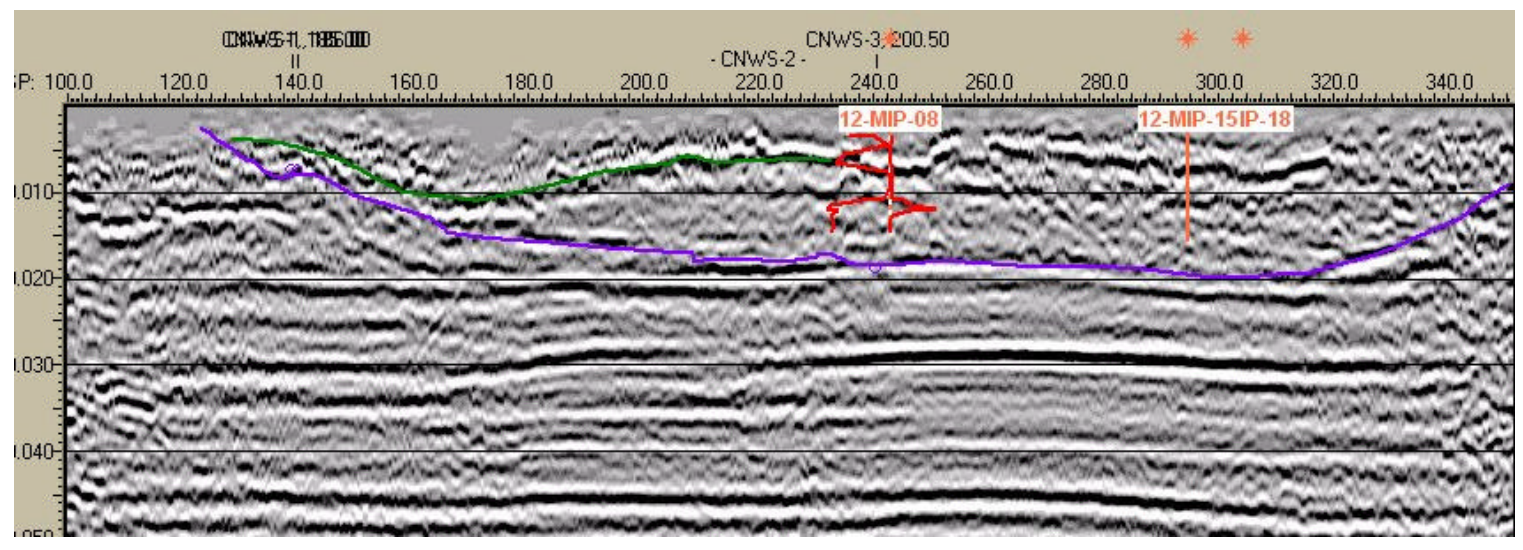

Figure 11. Seismic profile CNWS-2 was acquired from southwest to northeast. As in Figure 10 the two prominent features are the purple line, which is the base of a major channel scour, and the green line, which is the smaller and younger channel scour that incised into the older channel.

In Figure 11 (CNWS-2) the two prominent features are the large older purple channel scour and the smaller and younger green channel scour. These two features correlate with the same channel scours observed on seismic profile CNWS-1. It appears from the geometry of the lower scour (purple) that the seismic profile has crossed this feature at a oblique angle almost parallel with the depositional dip of the channel. The upper channel feature (green) also appears to be more elongated, in the cross-section view, on seismic profile CNWS-2 than on CNWS-1. On the seismic profile, it appears the profile has cut the channel feature at a slight oblique angle too. Based upon the DNAPL concentration data, the green channel scour is controlling the spatial geometry of the contaminant plume and, even though the base of the channel is a sandy clay, it is retarding downward migration of the DNAPL plume.

Figure 12 is an amplitude presentation of seismic line CNWS-3. The two major features on this seismic profile are the lower major channel scour (purple) and a smaller channel scour within the larger channel feature (green). The green channel is not the only channel feature within the larger channel. However, based upon the DNAPL concentration data, the green channel is controlling the plume geometry. Also note on Figure 12 the location of 12-MIP-12. A substantial increase in the ECD (right side) occurs at about $10 \mathrm{~ms}$, which is located at the base of the small sand at the base of the green channel. 


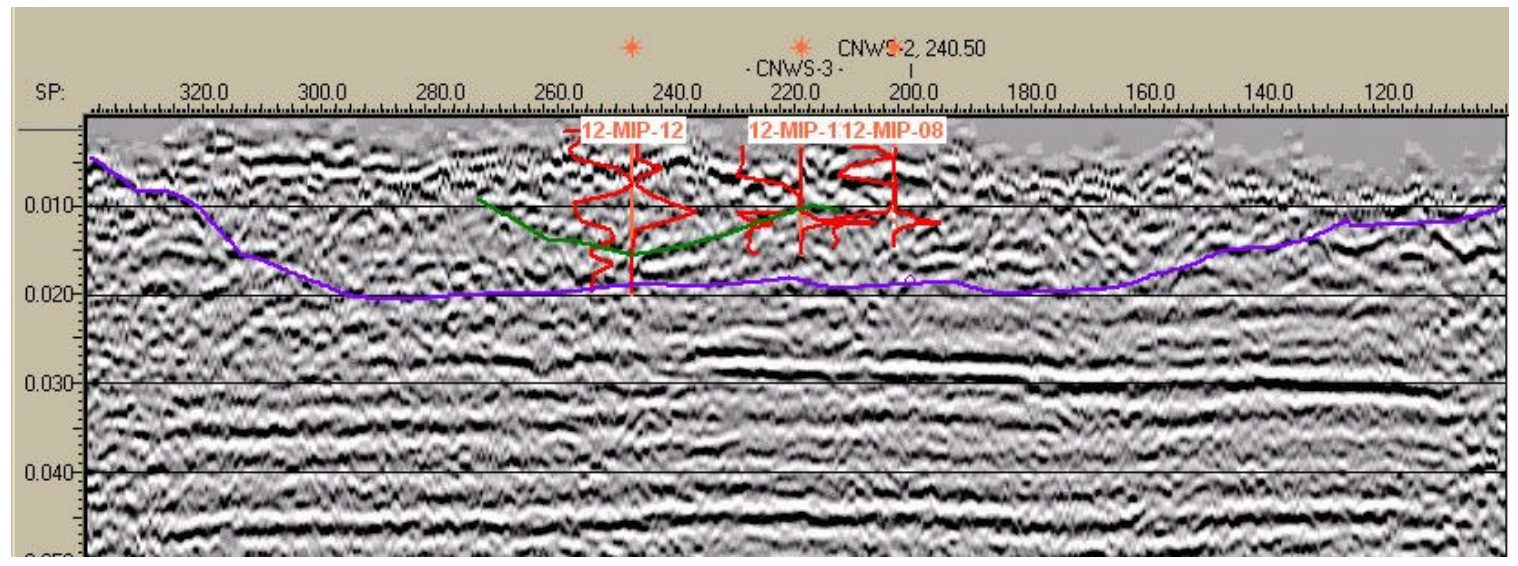

Figure 12. Seismic line CNWS-3 was acquired from southeast to northwest. The two major events are the purple line interpreted to be the base of a major channel and the green line a smaller channel.

\subsection{AVO Interpretation}

Amplitude variation with offset (AVO) analysis can be as simple as processing the seismic data into offset range stacks such as the project team used at the M-area seepage basin and at the Dynamic Underground Stripping (DUS) site at the M-Area solvent tank area, Savannah River Site. Other techniques such as gradient stacks (Castagna et al., 1998) and Poisson's Ratio stack (Vern and Hilterman, 1995) are used extensively in the petroleum industry for direct hydrocarbon detection. At the Charleston Naval Weapons Station the modeling data (Figure 8) suggest that if DNAPL is present in both the lower part of Unit 1 sand and the upper part of Unit 2 sandy clay, the amplitude response would be a bright spot, i.e. a negative amplitude becoming more negative with increase in offset. A bright spot is also indicative of lithology change as well as change in fluid type within the pore spaces. Therefore, a bright spot would not necessarily mean a change in fluid type along an interface.

Castagna (1998) stated that AVO interpretation could be enhanced by crossplotting the AVO intercept (A) and gradient (B) provided that reasonable petrophysical parameters are used so that a well defined background trend in the A-B plane is present. The B term (gradient) is the second term from the Shuey (1985) approximation of the Zoppritz equations, which describes the amplitude characteristics from 15 degrees of offset to 30 degrees of offset (immediate angles of offset). In the shallow subsurface the background trend is generally positive. Any deviation from the background tend is a very good indicator of the presence of DNAPL or a change in the lithology with non-normal elastic properties. Simply put, the AVO gradient is the change in slope of the reflection coefficient with increase in offset (Graul, 2001). In Figure 8 the slope of the line on each of the graphs (reflection coefficient versus offset) is the gradient. At the CNWS, there is excellent control of the geology in the area of contamination. Therefore, any change in background is believed to be attributed to a change in fluid in the pore spaces, i.e. DNAPL and not some drastic change in the geology. 
The other AVO interpretation technique used in this study is the Poisson's ratio stack, which is a stack generated from the product of Poisson reflectivity and the (NI) normal incidence reflectivity (Vern and Hilterman, 1995). This is the change of Poisson's ratio across an acoustic interface with offset. The scaled Poisson's Ratio stack is derived from Shuey's approximation of Zoeppritz equations and represents angles of offset greater than 30 degrees. Any changes observed on the Poisson's stack would suggest a change in fluid type since there is no indication there is a change in the geology. 


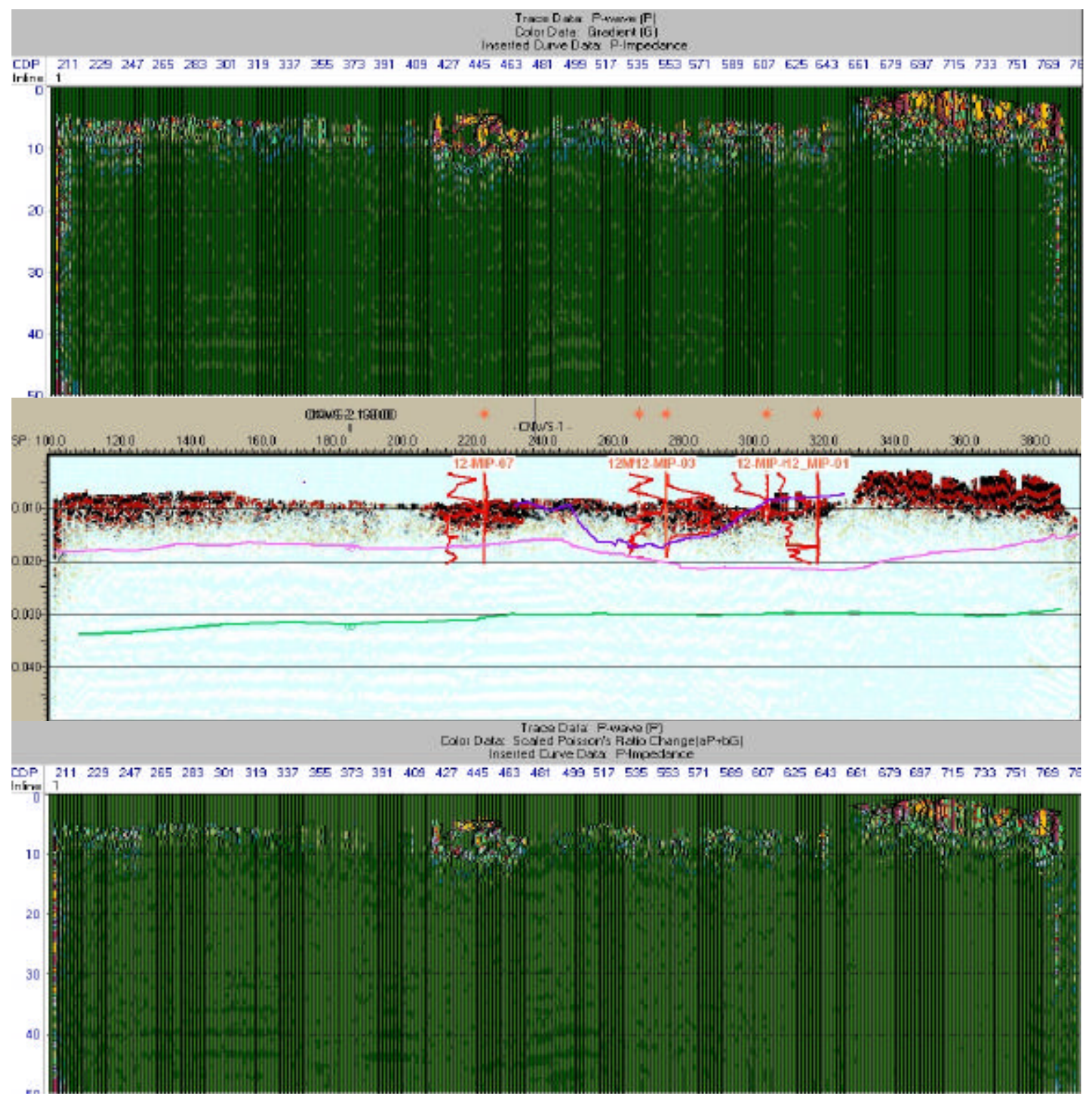

Figure 13. The upper (Figure 13A) and middle figure (Figure 13B) is the gradient stack for seismic profile CNWS-1. Figure 13B is the gradient stack plotted in another software package with the geologic interpretations and MIP probe data added. The left curve is conductivity and the right curve is ECD. Figure 13C is the scaled Poisson's ratio stack. 


\subsubsection{Seismic Profile CNWS-1}

In Figure 13, Figures 13A and 13B are the gradient stack (upper, middle) and Figure 13C (lower) is a scaled Poisson's ratio stack. On the gradient stack there are several bright anomalies the first starts at CDP 211 and extends to CDP 373, the second starts at CDP 410 to CDP 470, the third CDP 500 to CDP 643, and the fourth starts at CDP 660 and extends to the end of the line.

In conducting AVO analysis on shallow near surface data, the project team has observed that there is an edge effect when performing near and far range limited stacks, gradient stacks, and Poisson's ratio stacks. It appears that when there are not enough offsets such as in the beginning of the data and at the end of the data erroneous amplitude anomalies occur (examples Figures A, B, and C, the first and fourth anomalies). During field operations, the shot is "walked" into the spread until the shot reaches full spread and the spread begins to roll-along. Until the shot location has moved a number of stations equal to the half the recording spread length the CDP gathers are not populated with the full complement of source-receiver offsets. At the end of the line, the same is also true as the shot is "walked" off the spread.

The second anomaly between CDP 410 and 470 occurs below an asphalt road. This phenomenon is also observed on lines CNWS 2 and 3 where the seismic profiles cross the asphalt road. The anomaly may be the result of not having the full set of offsets in the CDP gather. This occurs because the data beneath the road was of poor quality and some of the shots were edited prior to final processing of the gathers. Another possibility is that the asphalt composition might have caused the anomaly.

The anomaly between CDP 500 and 643 on Figure 13A and between shot points 250 and 320 on Figure 13C is interpreted to be not the result of an edge effect or asphalt, but the result of a change in the pore fluids. Based upon the models (Figure 8), if DNAPL replaces water in either only Unit one or replaces water in the base of Unit 1 and the top of Unit 2 there would be an AVO anomaly and consequently a change in the AVO gradient. In the area of CDP 550 (shot point 275, Figure 13B) there is a pronounced AVO anomaly even though it appears to be faint on the Figures $13 \mathrm{~A}$ and 13C. This particular anomaly is well out of the influence of the edge effect at the end of the survey or the asphalt road; therefore, it appears that it is the result of DNAPL either partially replacing or completely replacing the pore waters. This particular area is adjacent to well $12 \mathrm{MW}-01$, which has high concentrations of DNAPL. Notice the location of 12MIP-03 (Figure 13) the ECD curve is has a blocky appearance, which is due to chlorinated solvents concentration exceeding the maximum range of the probe.

In addition to AVO gradient and Poisson's ratio stacks, another robust AVO interpretation technique is range limited offset stacks (Graul, 2001). In Figure 14 are the near and far offset range limited stacks for seismic profile CNWS-1. Based upon the model (Figure 8 ) if there is no DNAPL is present, the amplitudes should be negative on the near offsets and become positive on the far offsets. In Figure 14 the upper figure is the range limited offset stack for the offset range from 0 degrees to 30 degrees. At approximately $10 \mathrm{~ms}$, between CDPs 535 and 689 the amplitudes are all negative, which is what the model indicates for the absence of DNAPL. However, according to the model if both units 1 and 2 have DNAPL, then the amplitudes become more negative which is perhaps influencing the amplitudes on the near offset 
stack. On the far offset stack at the same intervals, the amplitudes become positive. Because the interpretation of range limited stacks is not clear, gradient and scaled Poisson's ratio analysis were performed on the data sets.

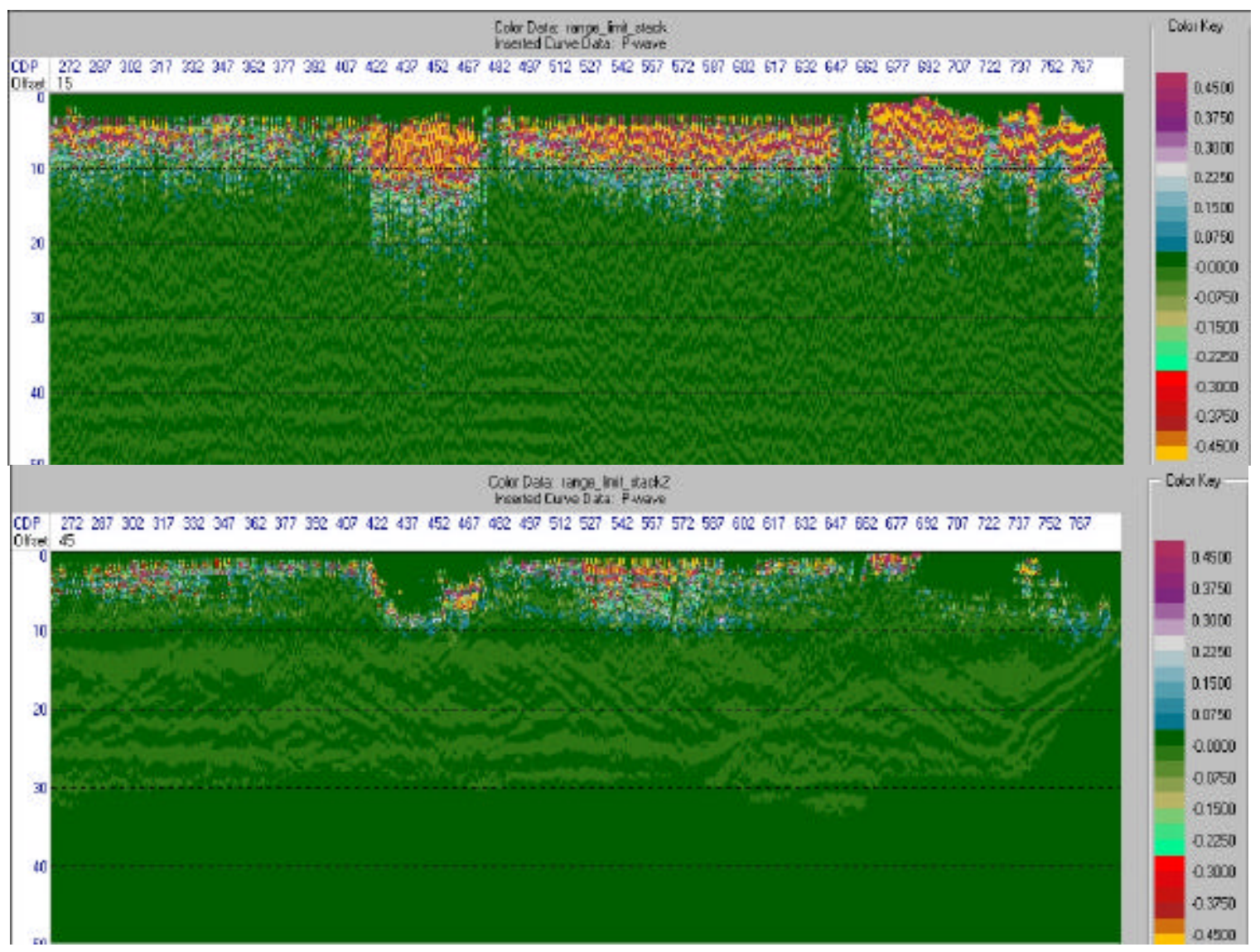

Figure 14. Figure 14 is range limited offset stacks for seismic profile CNWS-1. Figure 14A (upper figure) is the range limited stack with offset ranges from 0 degrees to 30 degrees and Figure 14B (lower figure) is range limited stack with offset ranges from 30 degrees to 60 degrees. 


\subsubsection{Line Seismic CNWS-2}

Figure 15 are gradient stacks (A and B) and scaled Poisson's ratio stack for seismic line CNWS-2. Seismic line CNWS-2 is similar to seismic line CNWS-2 in that the edge effects produce anomalous features at the beginning and end of the seismic line. As on CNWS1 , the edge effect is more prominent on the end of the line than at the beginning of the line. If the anomalies at the beginning and at the end of the seismic line are discarded, there appears to be no amplitude variations that can be associated with DNAPL. At the top of the data, occurring at approximately $10 \mathrm{~ms}$, there is a thin zone that is visible across the entire line, but is believed to be just an artifact from the AVO analysis. There is one anomaly between CDP 320 and 370 (Figures 15A and 15C) (between 160 and 185, Figure 15B) that is due to the seismic line crossing an asphalt road. MIP 12-MIP-18 is located slightly off the seismic line (Figure 15B) and the ECD did not give a significant response. 


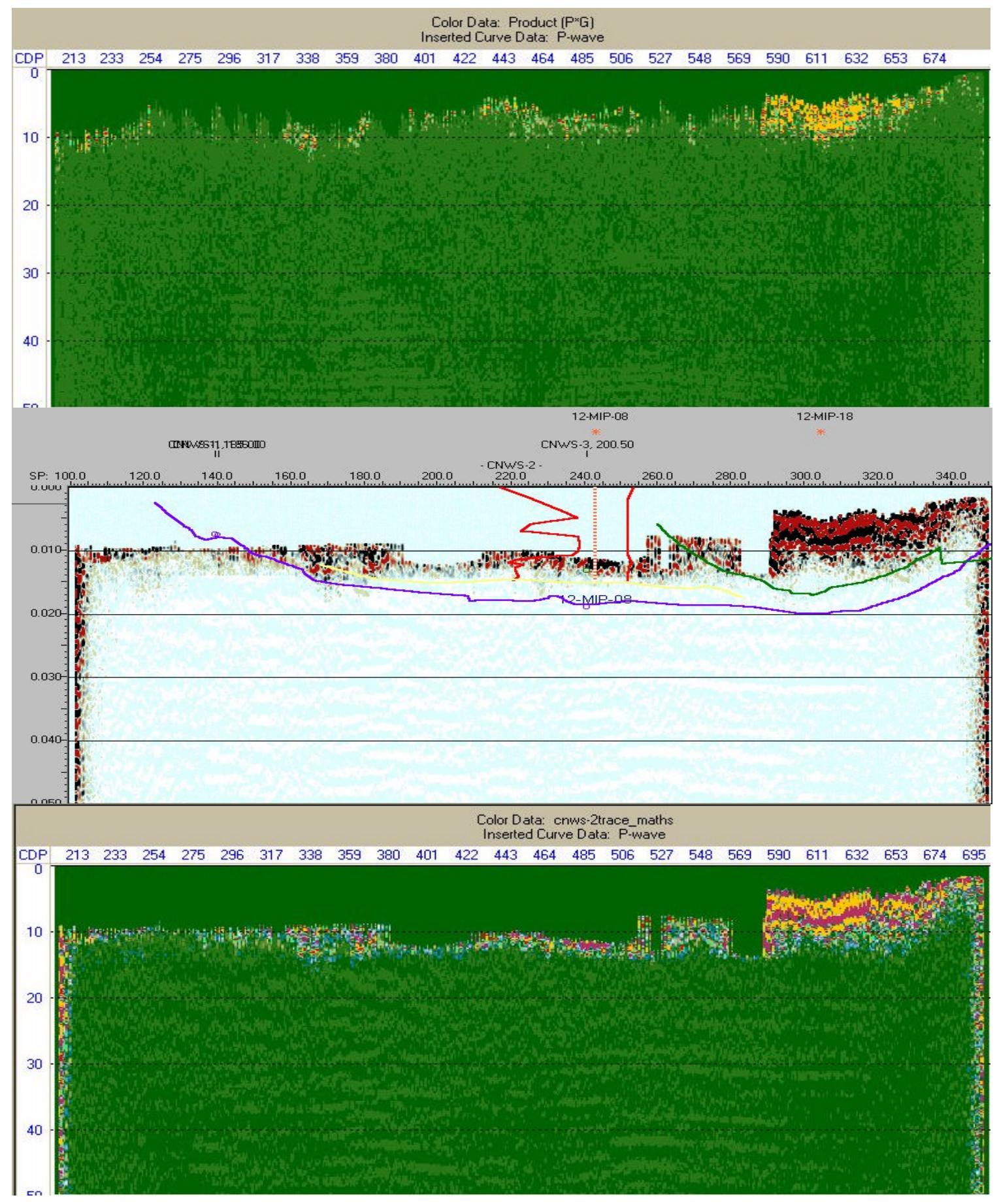

Figure 15. Figure 15A is gradient stack of seismic line CNWS-2, Figure 15B is gradient stack with geologic interpretations and conductivity log (left) and MIP ECD curve (right) for MIP 12MIP-08, and Figure 15C is scaled Poisson's ratio stack. 


\subsubsection{Seismic Line CNWS-3}

Figure 16 is a series of AVO analyses preformed on seismic line CNWS-3. The AVO analysis consists of gradient stacks (Figures A and B) and scaled Poisson's ratio stack (Figure C). The only AVO anomaly, besides the artifacts generated from edge effect, is located between CDPs 400 and 402 (Figures A and C) and between shot points 200 and 210 (Figure B). The anomaly is mostly attributed to an artifact caused by editing traces where the seismic line crossed an asphalt road. On Figure 16B MIP location 12-MIP-08 was drilled through the middle of the anomaly and there was no significant response from the ECD probe. 


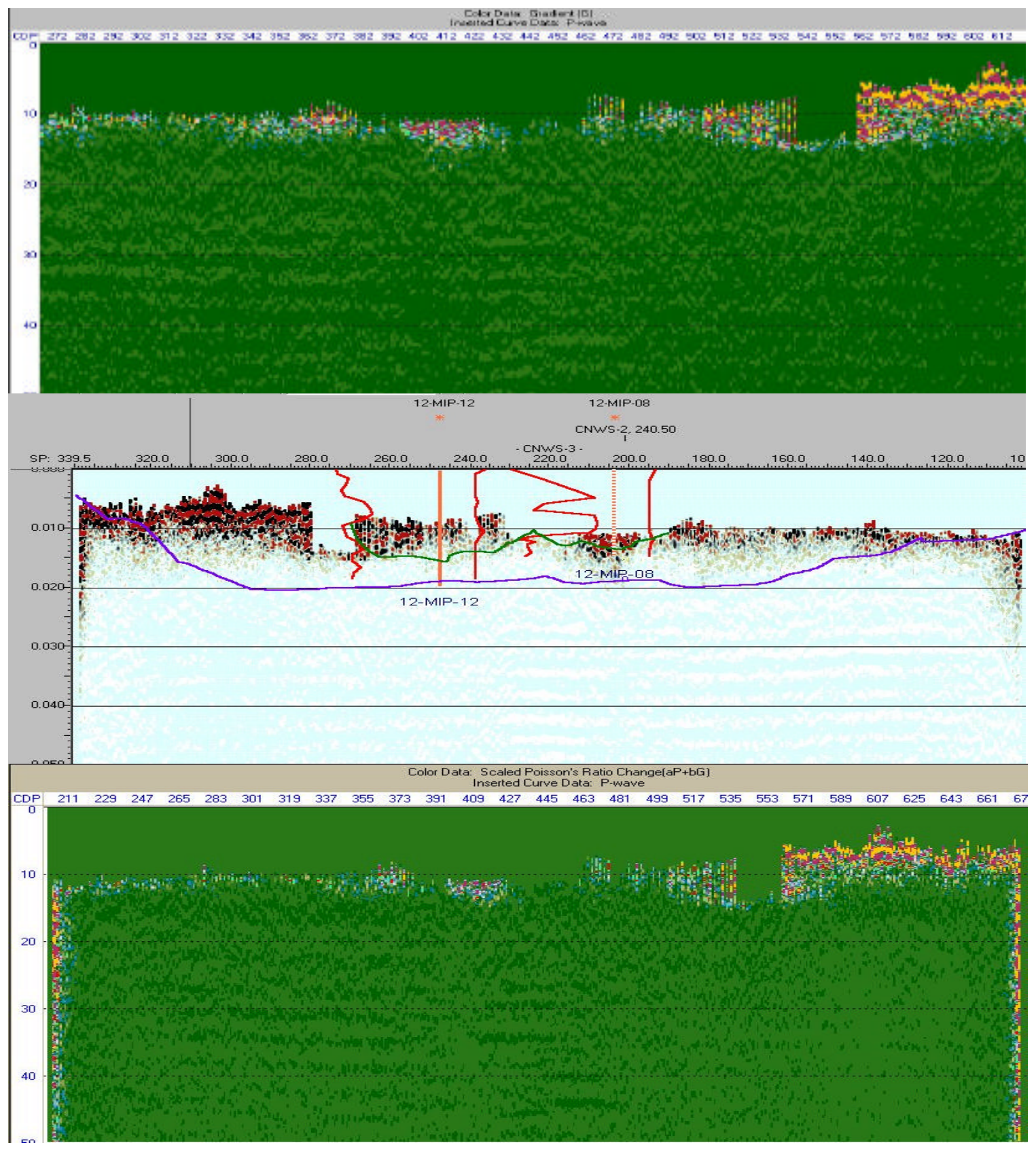

Figure 16. Figure 16A is gradient stack of seismic line CNWS-3, Figure 16B is also a gradient stack with the geologic interpretations, conductivity log (left curve) and MIP-ECD (right curve) and Figure 16C is a scaled Poisson's ratio stack. 


\subsection{Validation}

In all the previous studies conducted by the project team a criticism has been the validation of the results. At Savannah River Site, M-Seepage Basin the project team believes there are enough existing wells to validate the results of the study. However, the critics said no wells were drilled in areas where anomalies were absent to demonstrate that no anomaly indicates no DNAPL.

The Charleston Naval Weapons Station site offered a unique opportunity to the project team in that several locations were drilled where AVO anomalies were present and where AVO anomalies were absent. The project team drilled areas where, upon further analysis, it was determined that the anomaly investigated was an artifact associated with an asphalt oads (Figure 1, solid diamonds and Figure 17). In Table 8 are the MIP locations selected by the project team and their predictions based upon the AVO analysis. Figures 18 and 19 shows the concentration data of different solvents and daughter products from the water samples.

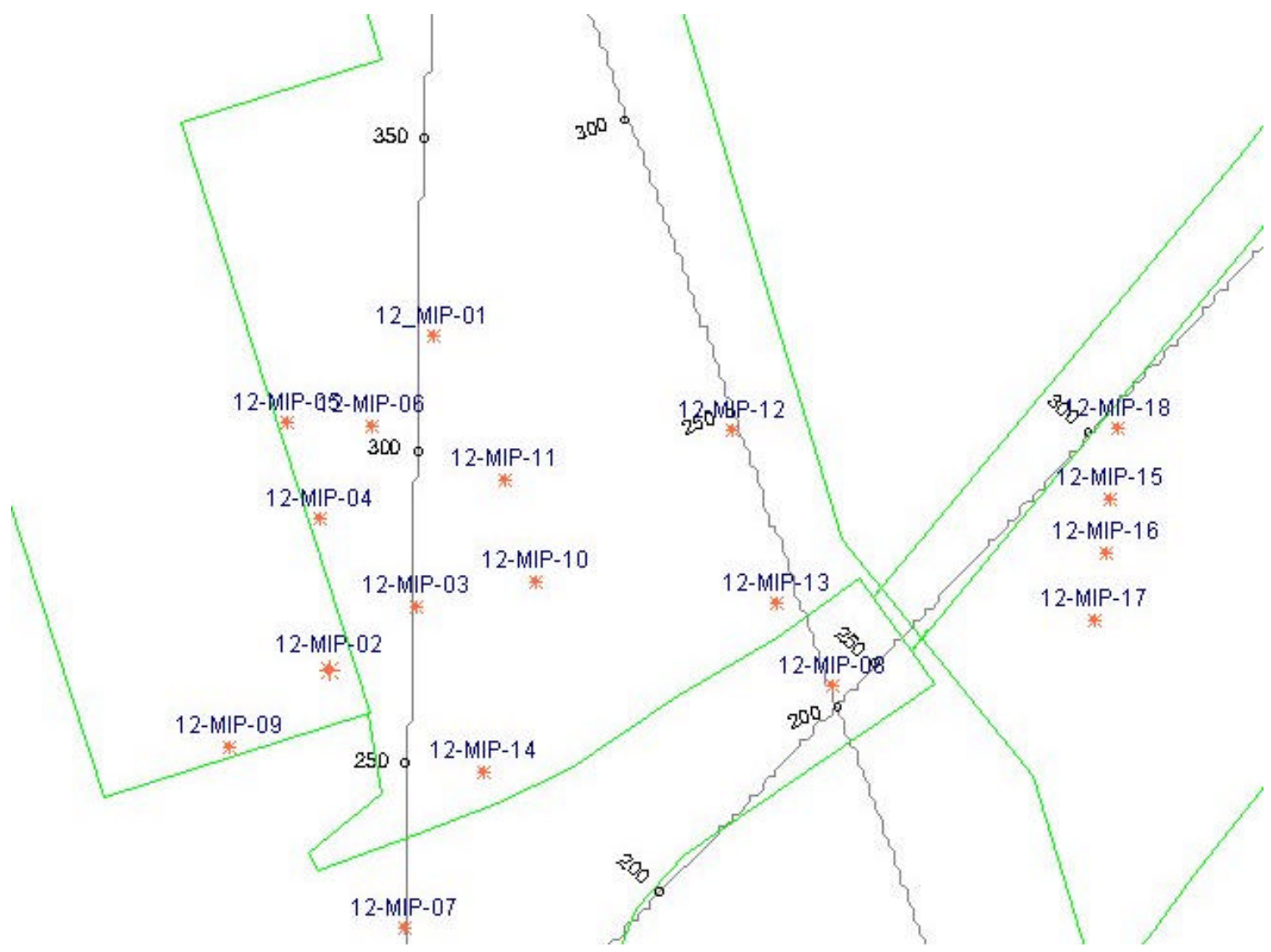

Figure 17. Figure 17 is an enlargement of Figure 1 so that the individual MIP names are recognizable. 
Table 8. The MIPs location chosen by the project team to test the AVO analysis and the predicted results using the MIP.

\begin{tabular}{|l|c|c|l|}
\hline MIP ID & Line Number & Shot Pt. Number & Prediction \\
\hline 12-MIP-01 & 1 & 318 & No high concentration \\
\hline 12-MIP-03 & 1 & 273 & High concentration \\
\hline 12-MIP-07 & 1 & 223 & No high concentration \\
\hline 12-MIP-08 & 3 & 203 & No high concentration \\
\hline 12-MIP-12 & 3 & 247 & No high concentration \\
\hline
\end{tabular}

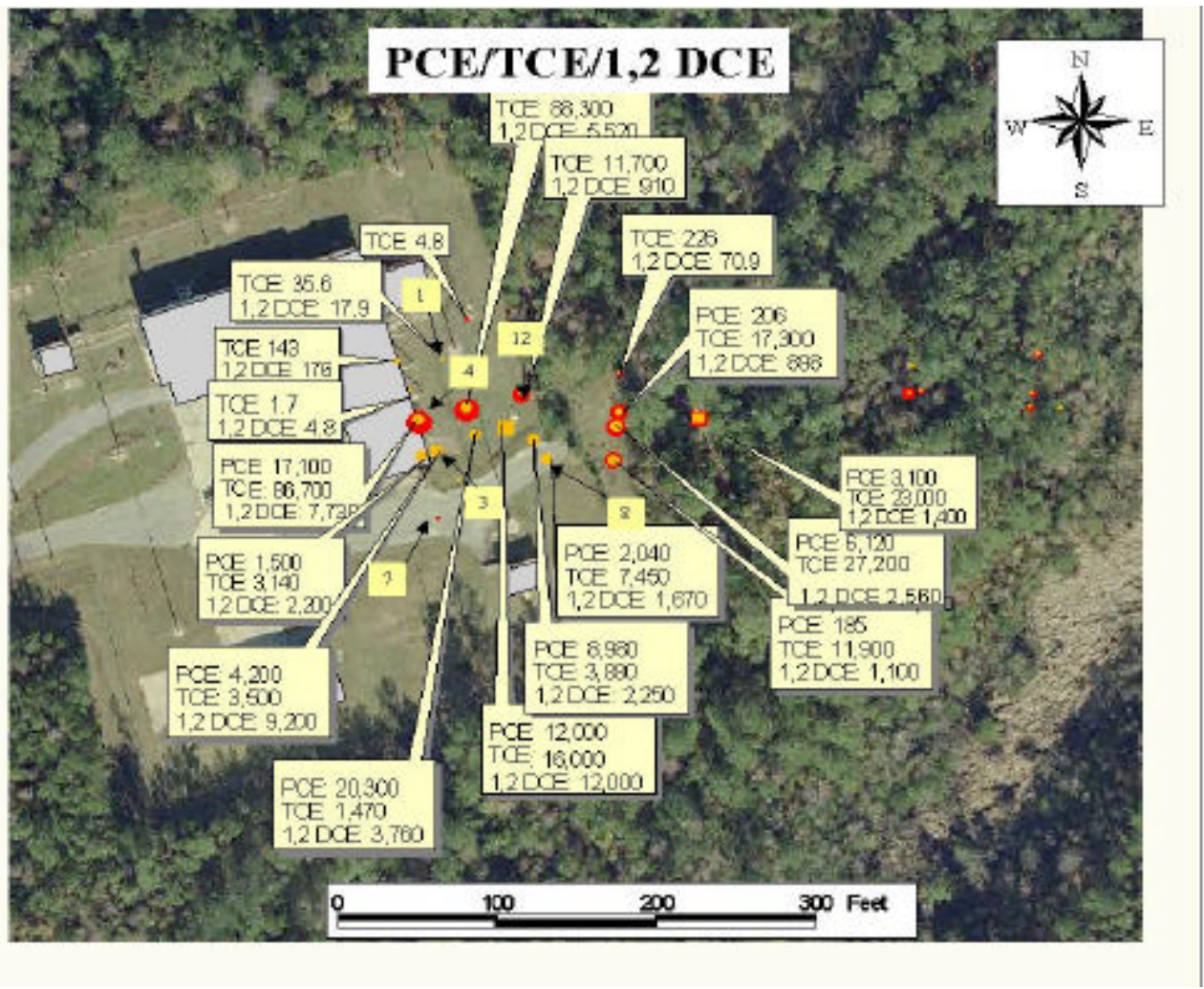

Figure 18. Location of water samples that were analyzed for TCA and 1,2 DCE. The yellow squares with a number are the MIP locations and the magenta and yellow circles are the locations where water samples were taken. Note that the water samples were taken within 2 feet of the MIP locations. Diagram provided by Naval Facilities Engineering Command Southern Division. Diagram provided by Naval Facilities Engineering Command Southern Division. 


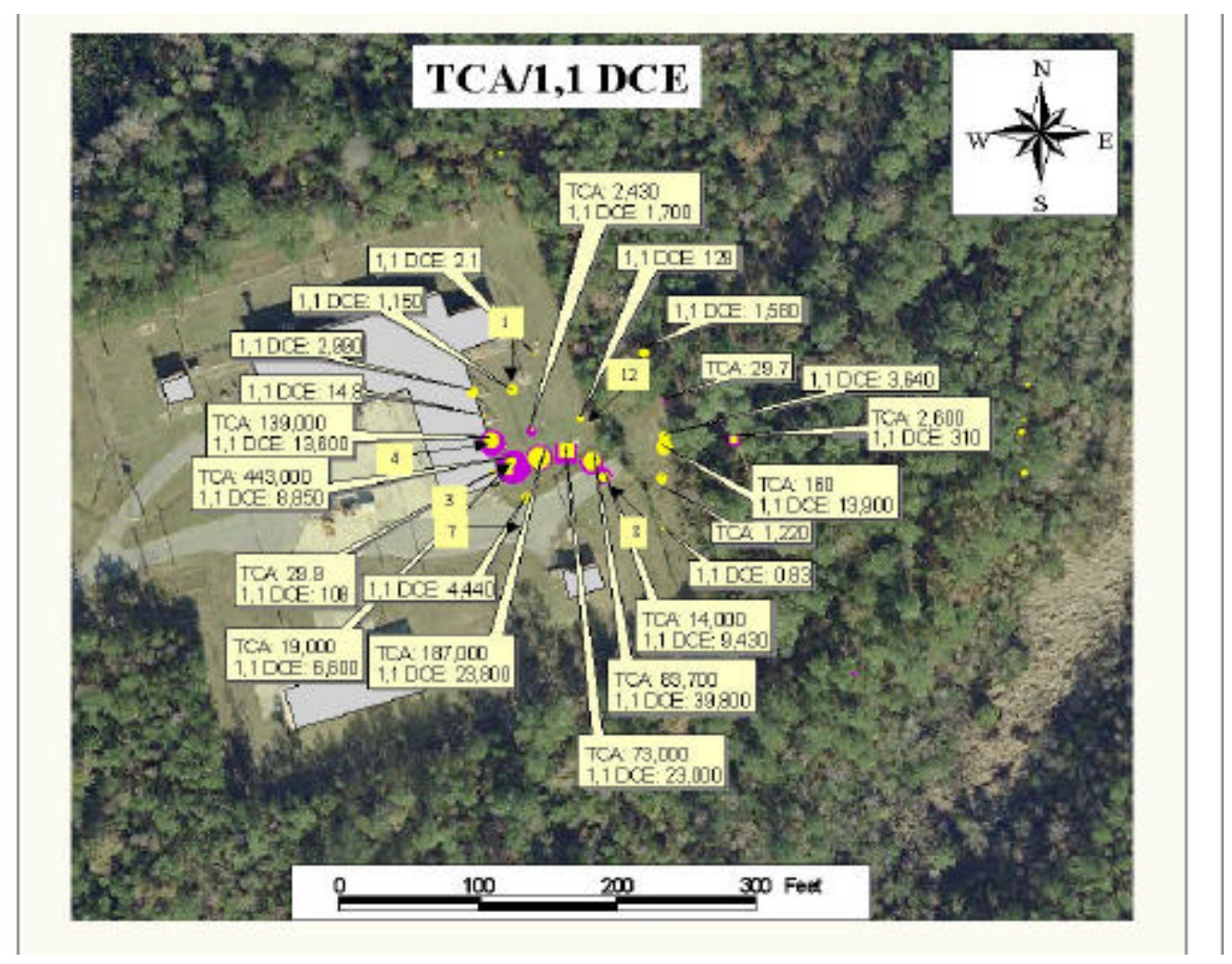

Figure 19. Location of water samples that were analyzed for TCA and 1,1 DCE. The yellow squares with a number are the MIP locations and the magenta and yellow circles are the locations where water samples were taken. Note that the water samples were taken within 2 feet of the MIP locations. Diagram provided by Naval Facilities Engineering Command Southern Division.

The water samples taken from the area adjacent to 12-MIP-03, which was selected based upon AVO analysis, had the highest concentration of TCA (Figure 19). MIP 12-MIP04 located adjacent to shot point 290 (Figure 14) was located in the same AVO anomaly as 12-MIP-03 and has the second highest concentration TCA and the second highest concentration of TCE (Figures 18 and 19). MIP locations 12-MIP-07 and 12-MIP-08 (Figures 18 and 19, labeled 7 and 8 in the yellow squares) were drilled though the asphalt anomalies. At 12-MIP-07 no water samples were taken because the MIP probe data indicated that there were no chemical contaminates present at that location, which is what the project team suspected. MIP location 12-MIP-08 there was a water sample taken adjacent to the location and the results were 14,000 ppb TCA, 9,430 ppb 1,1,DCE, 2,040 ppb PCE, 7,450 ppb TCE, and 1,670 ppb 1, 2 DCE. The total amount of chlorinated solvents and their daughter products is $34,590 \mathrm{ppb}$, which is mostly likely not enough to cause an AVO anomaly. Approximately 30 feet northwest of 12-MIP-08 another water sample was taken along seismic line CNWS-3. The concentrations were 83,700 ppb TCA, 39,800 ppb 1,1 DCE, 8,980 ppb PCE, 3,880 ppb TCE, and 2,250 ppb 1,2 DCE for a total of 138,610 ppb of chlorinated solvent and their daughter products. It appears that at that location there is not enough solvent 
to cause an AVO anomaly. If the asphalt road were not there, perhaps there would be a slight anomaly that could be detected.

\subsection{Conclusion}

Based upon the models and results of the different AVO analysis techniques applied to the data set, it appears that the project team was able to locate the area of the highest concentration of DNAPL. Unlike previous studies conducted using AVO analysis for direct detection of DNAPL, the project team was able to drill the anomaly to verify the results as well as drill in areas where the project team predicted there would not be high concentration of DNAPL. In the areas where the project team predicted no high concentration of DNAPL, no high concentration found. This does not mean that there were no concentrations of DNAPL above drinking water standards. It must be remembered hat this technique is designed to locate areas of highest concentrations whether DNAPL is only partially filling the pore spaces or completely replacing the interstitial fluids. Previous modeling studies as well as this study suggests that only $20 \%$ of the pore space need to be filled with DNAPL to cause an AVO anomaly. There were areas where the water samples had extremely elevated levels of solvents in excess of 130,000 ppb that appeared not to cause an AVO anomaly. In that instance, however, the anomaly may have been masked by the effects of an asphalt road.

\subsection{References}

Castagna, J.P. and Backus, M. M., eds. 1993, Offset-dependent reflectivity - Theory and practice: SEG Investigations in Geophysics No. 8, Society of Exploration Geophysicists, Tulsa, OK, 345 p.

Castagna, J.P, Swan H.W., and Foster, D.J, 1998, Framework for AVO gradient and intercept interpretation: Geophysics, v. 65, no. 3, p. 571-581.

Gardner, G.H.F., Gardner, L.W., and Gregory, A.R., 1974, Formation velocity and density-the diagnostic basics for stratigraphic traps: Geophysics, v. 39, p. 770-780.

Gassmann, F., 1951, Über die elastizität poröser medien: Vier. Der Natur. Gesellschaft in Zürich, p 96, 1-23

Graul, M., 2001, AVO seismic Lithology: SEG Continuing Education, San Antonio, TX.

Shuey, R.T., 1985, A simplification of the Zoeppritz equations: Geophysics, v. 50, no.4, p. 609-614.

Tetra Tech Nus, Inc., 2000, Draft report SWMU12-Former south side PCP treatment area, Naval Weapons Station, Charleston, South Carolina. 
Tsvankin, L, and Thomsen, L., 1994, Nonhyperbolic reflection moveout in anisotropic media: Geophysics, v.59, no.8, p1290-1304.

Verm, R. and Hilterman, F., 1995, Lithology color-coded seismic sections: The calibration of AVO crossplotting to rock properties: The Leading Edge, v. 14, n. 8, p. 847-853.

Zoeppritz, K., 1919, Uber reflexion und durchgang seismischer wellen durch Unstetigkerlsflaschen: Berlin, Uber Erdbebenwellen VII B, Nachrichten der Koniglichen Gesellschaft der Wissenschaften zu Gottingen, math-phys. K1., p. 57-84. 


\section{Appendix 1}

MIP logs consist of six columns (left to right): temperature curve, ECD curve, FID curve, PID curve, penetration rate, and soil conductivity curve. 


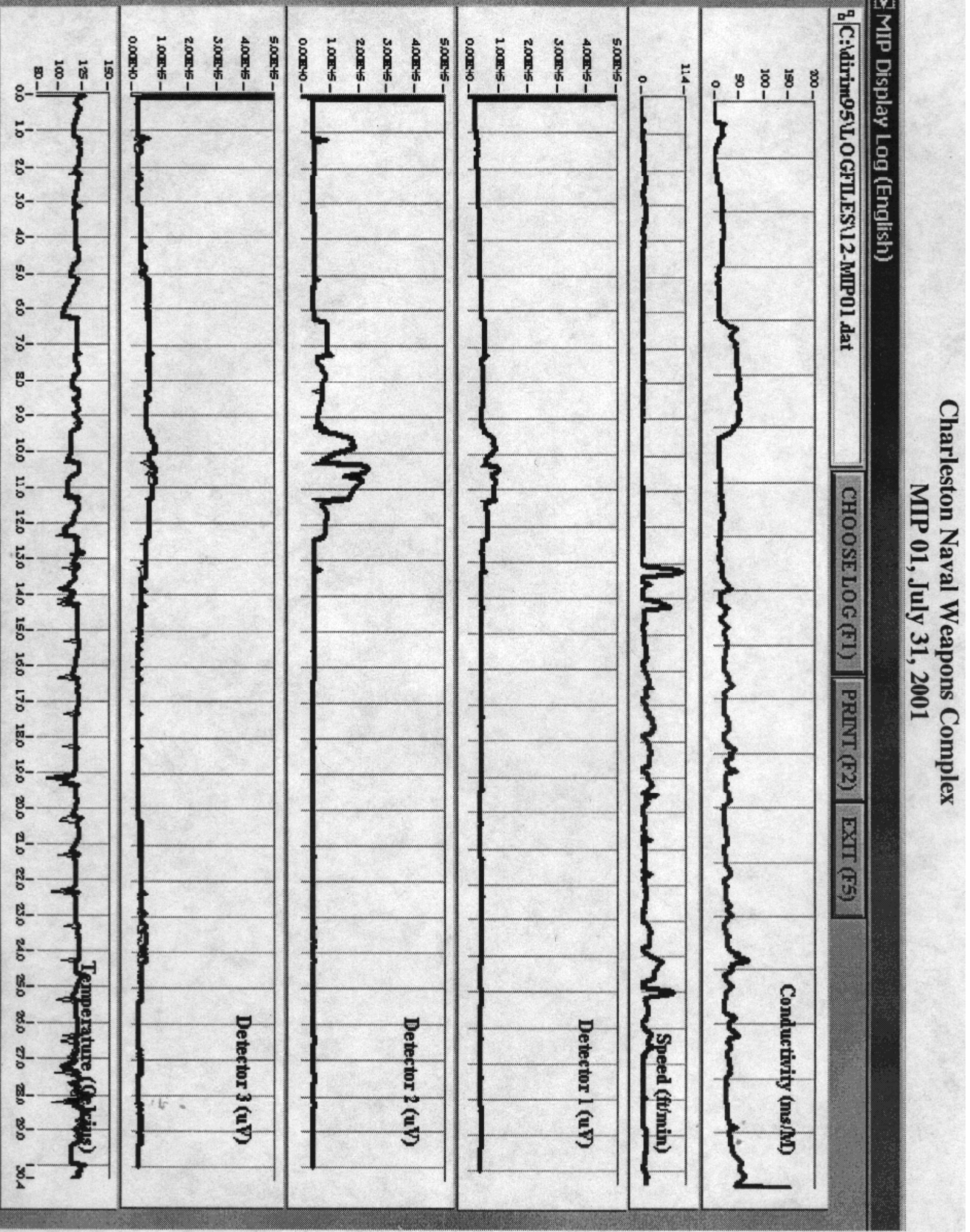




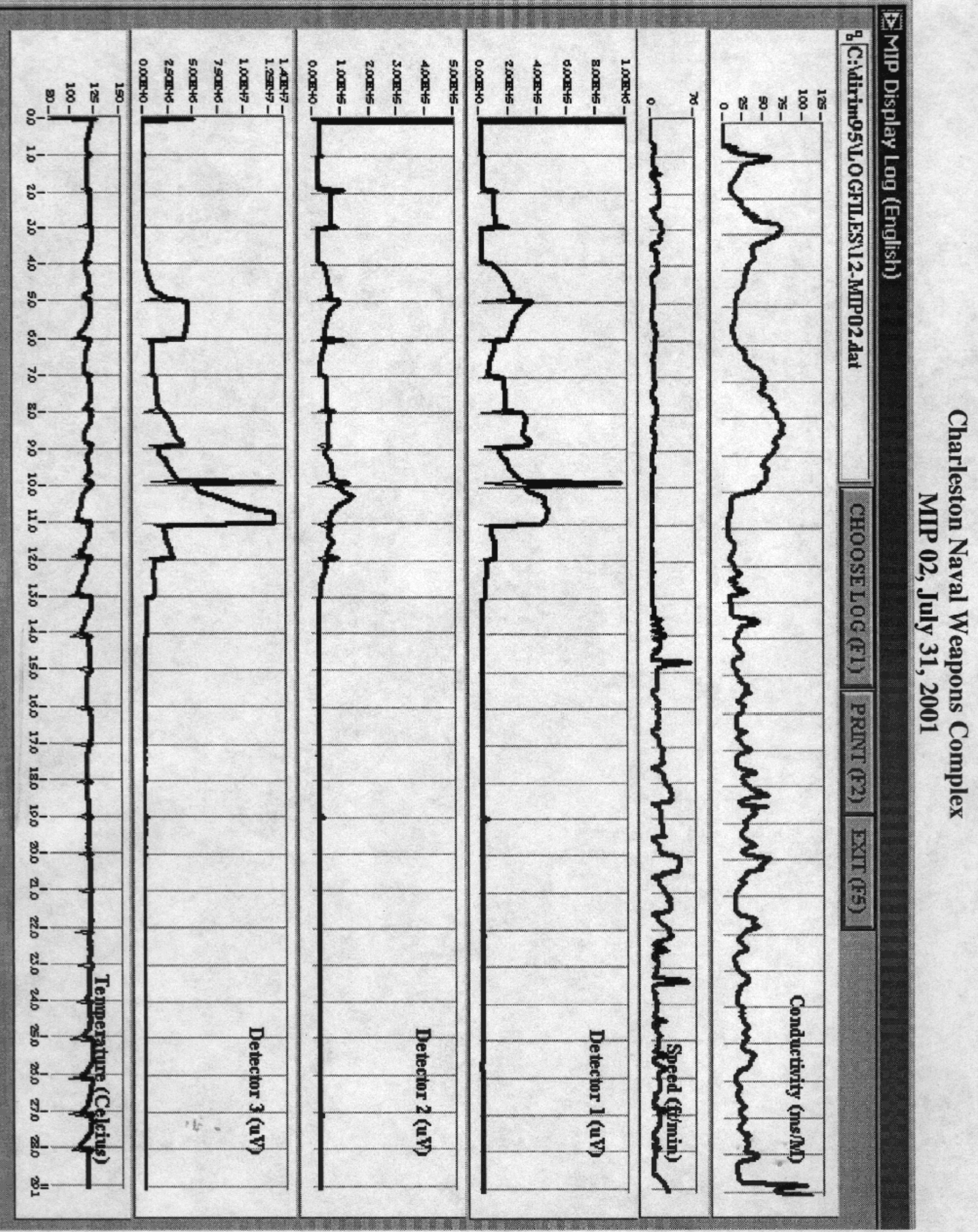




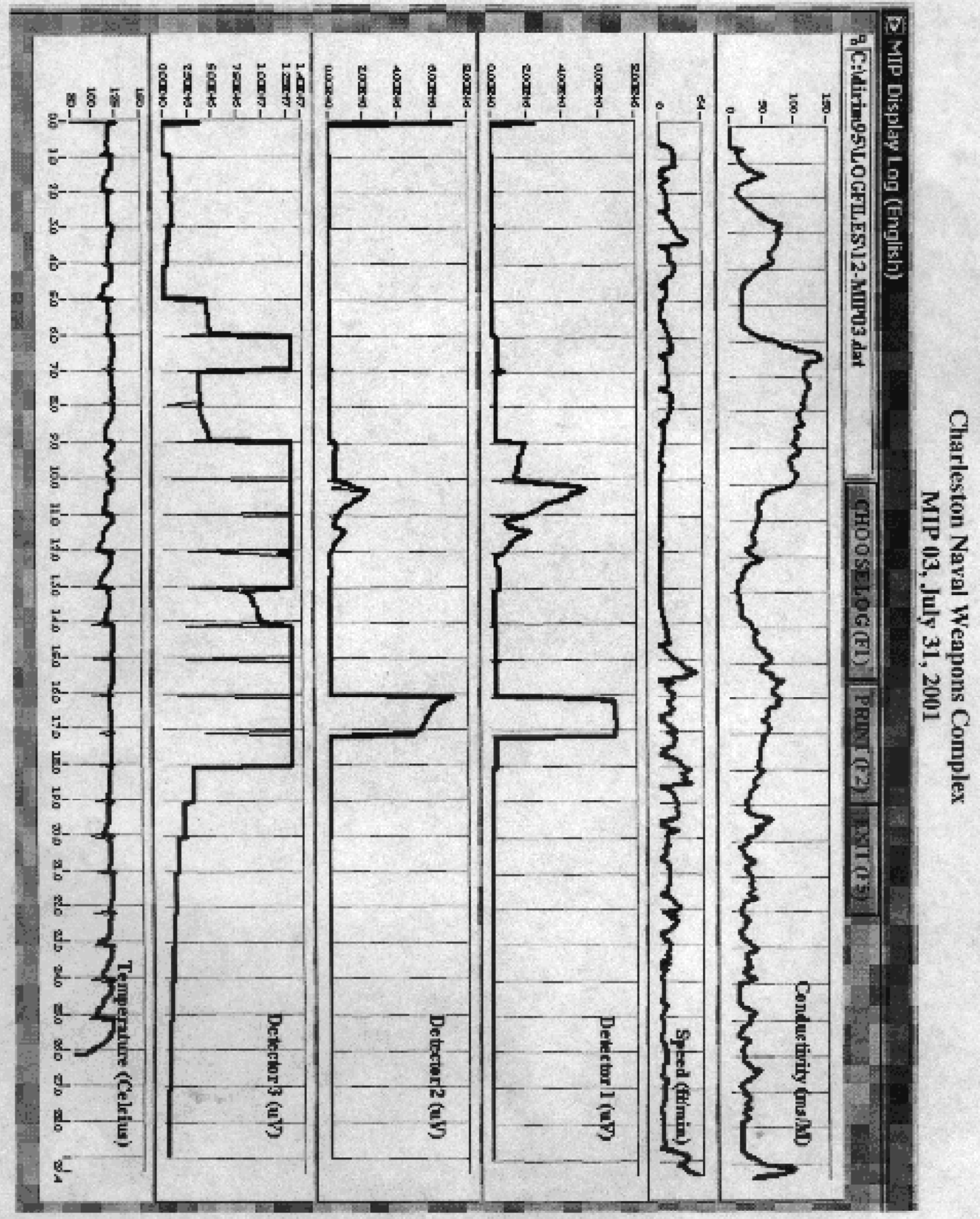




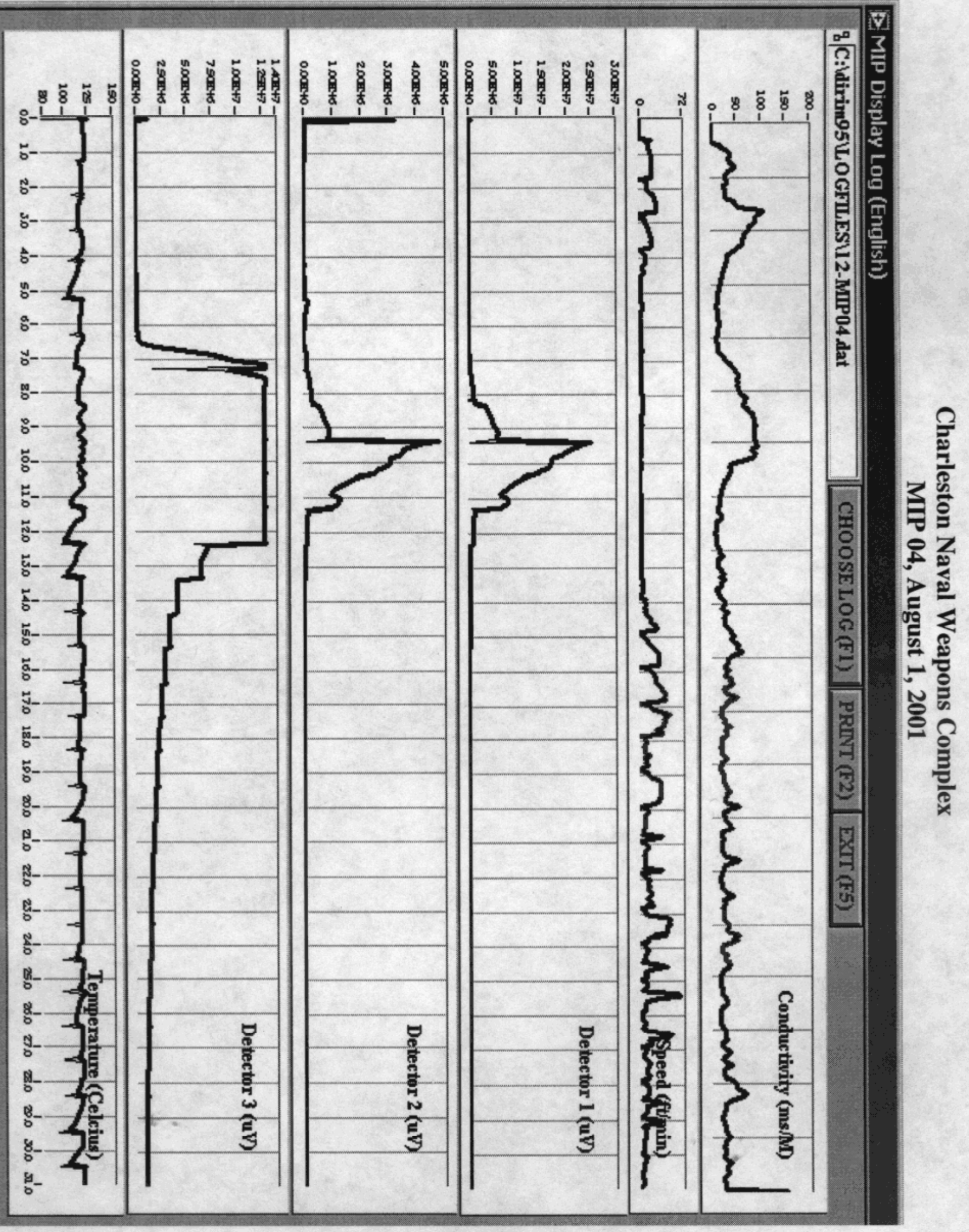




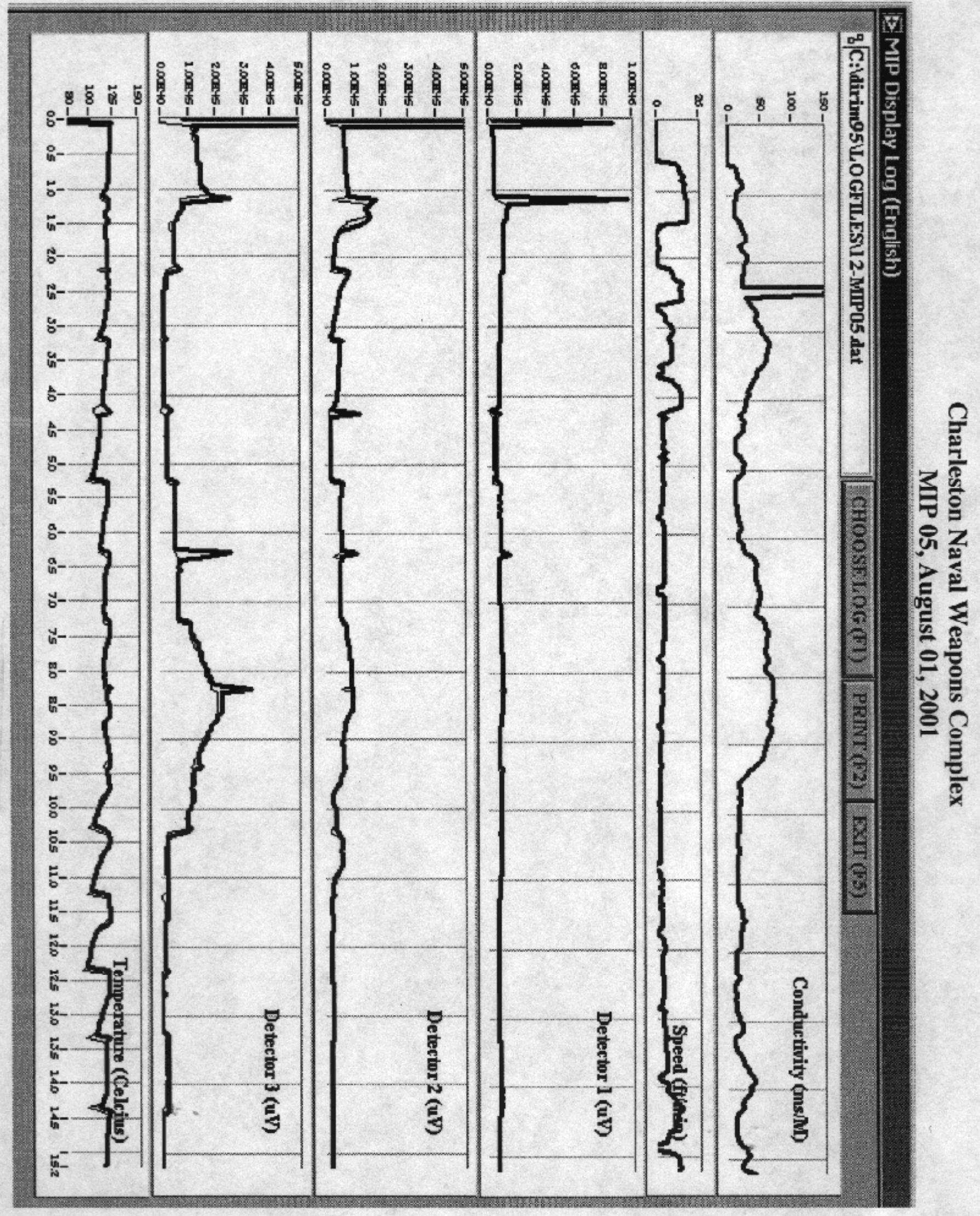




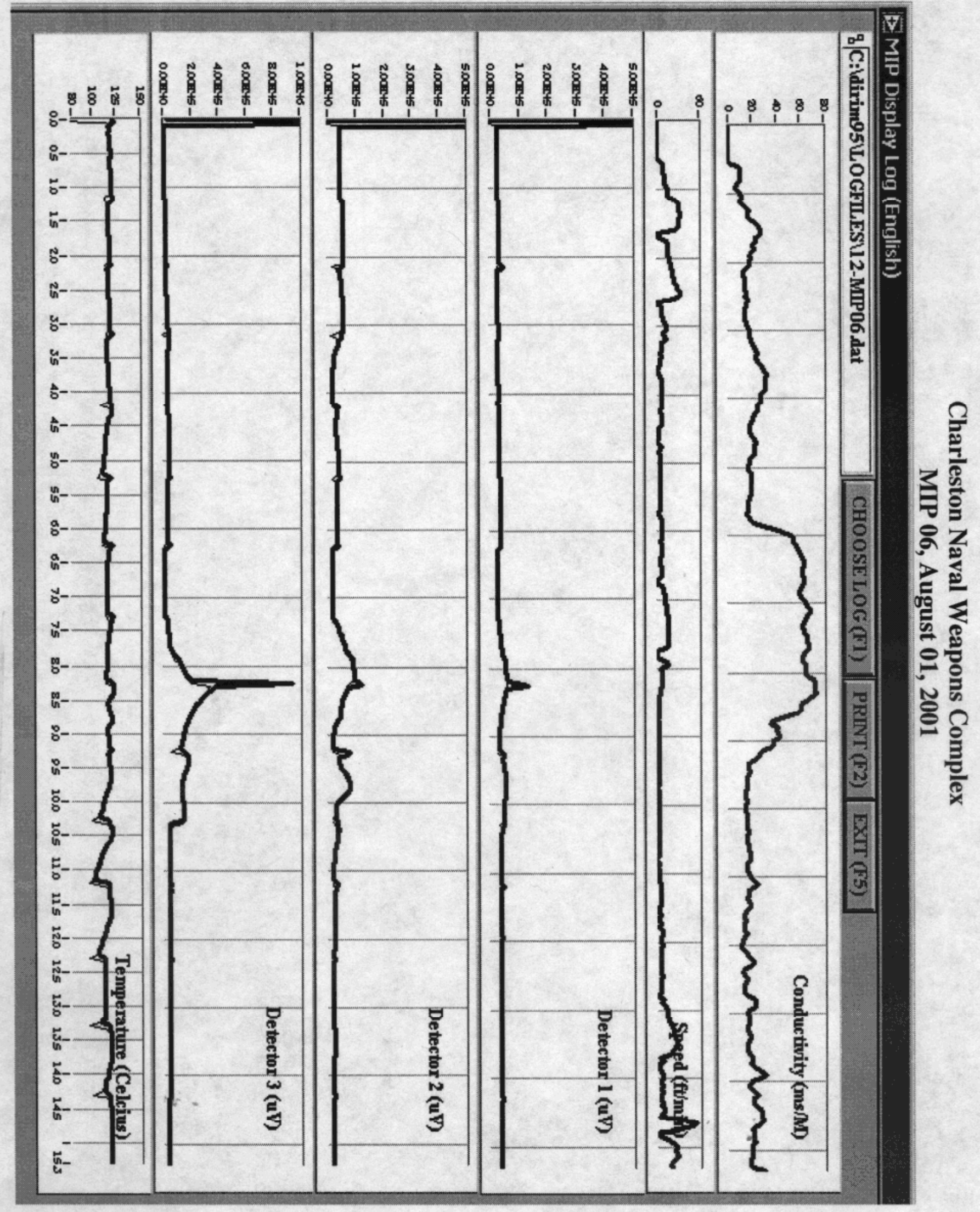




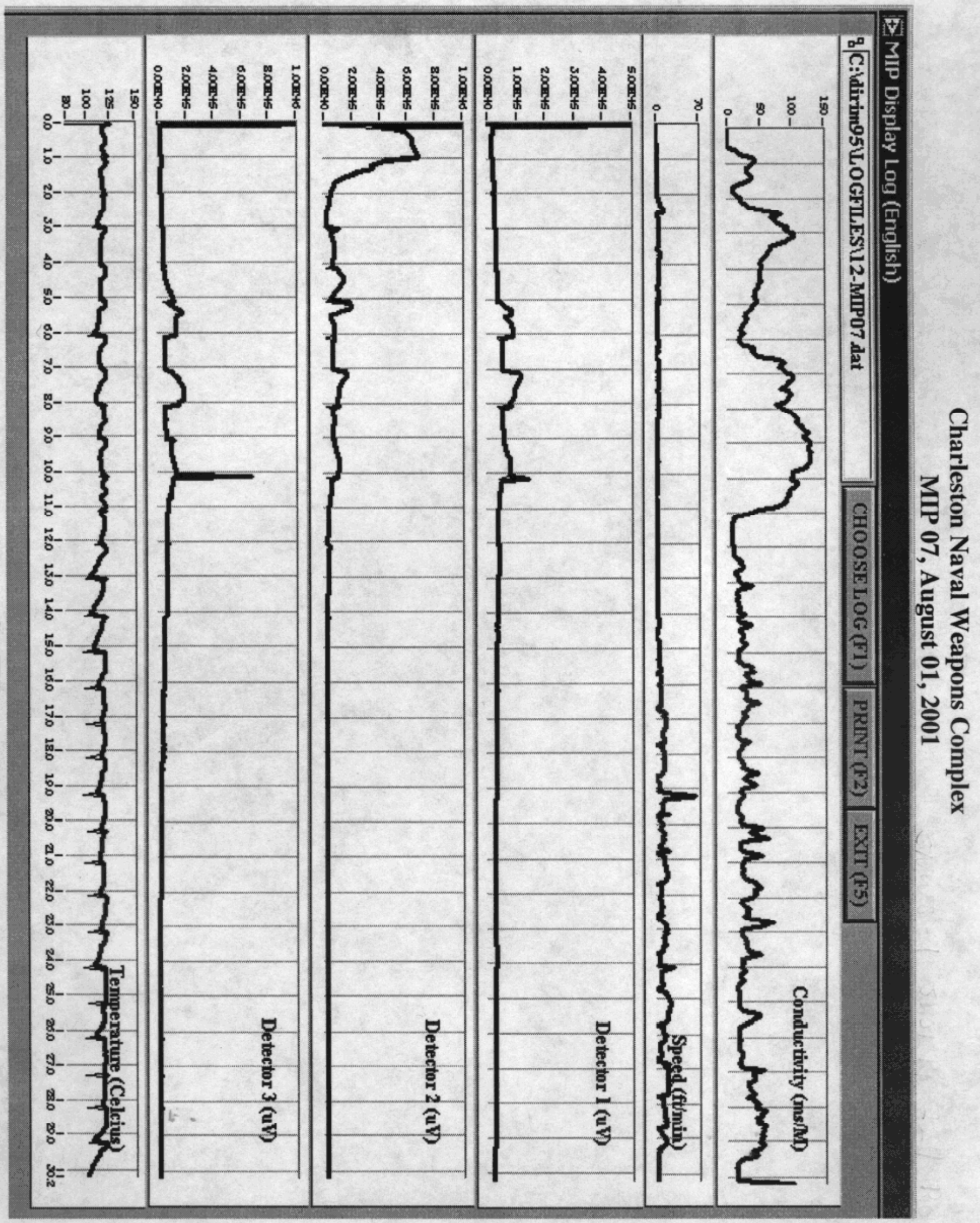




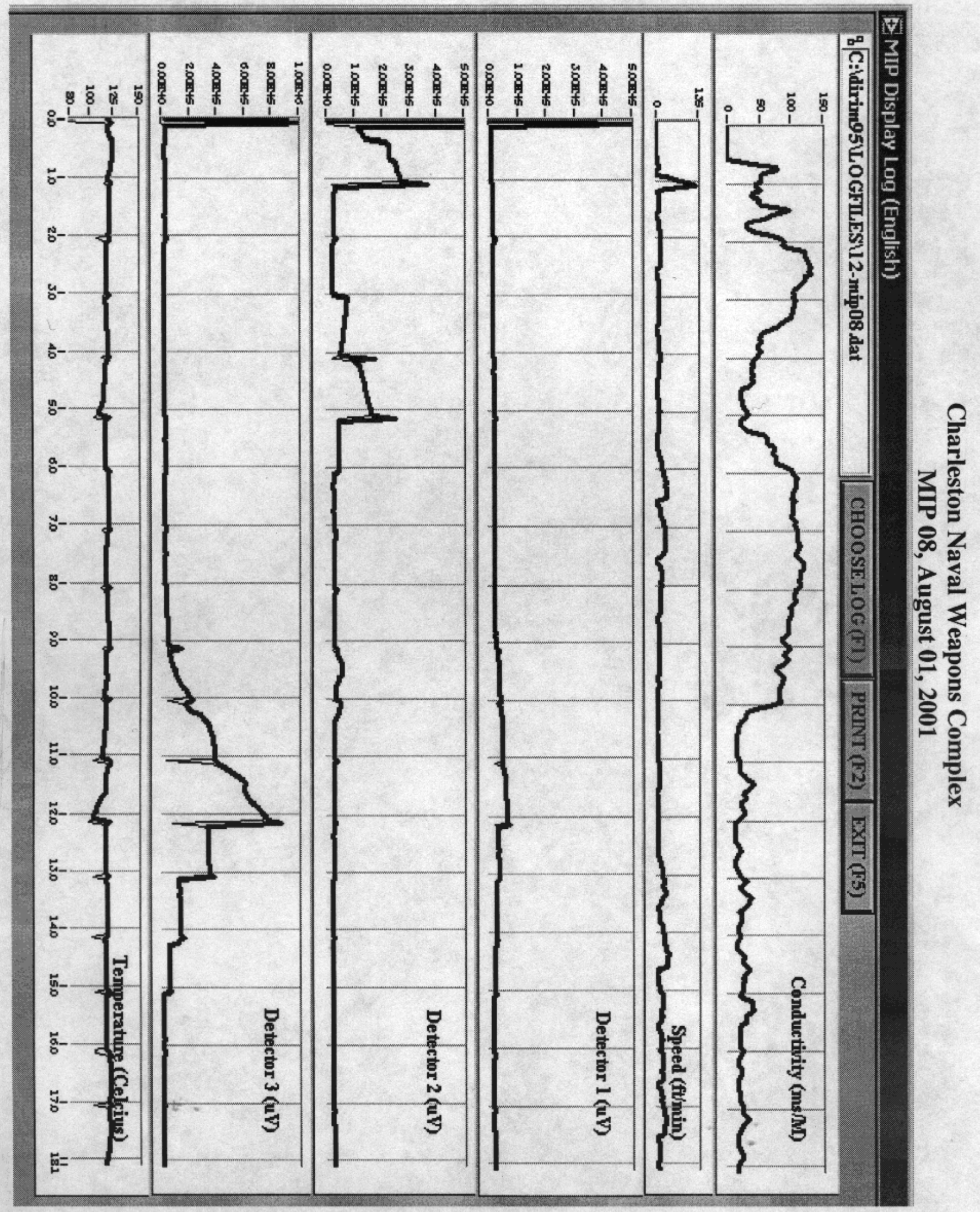




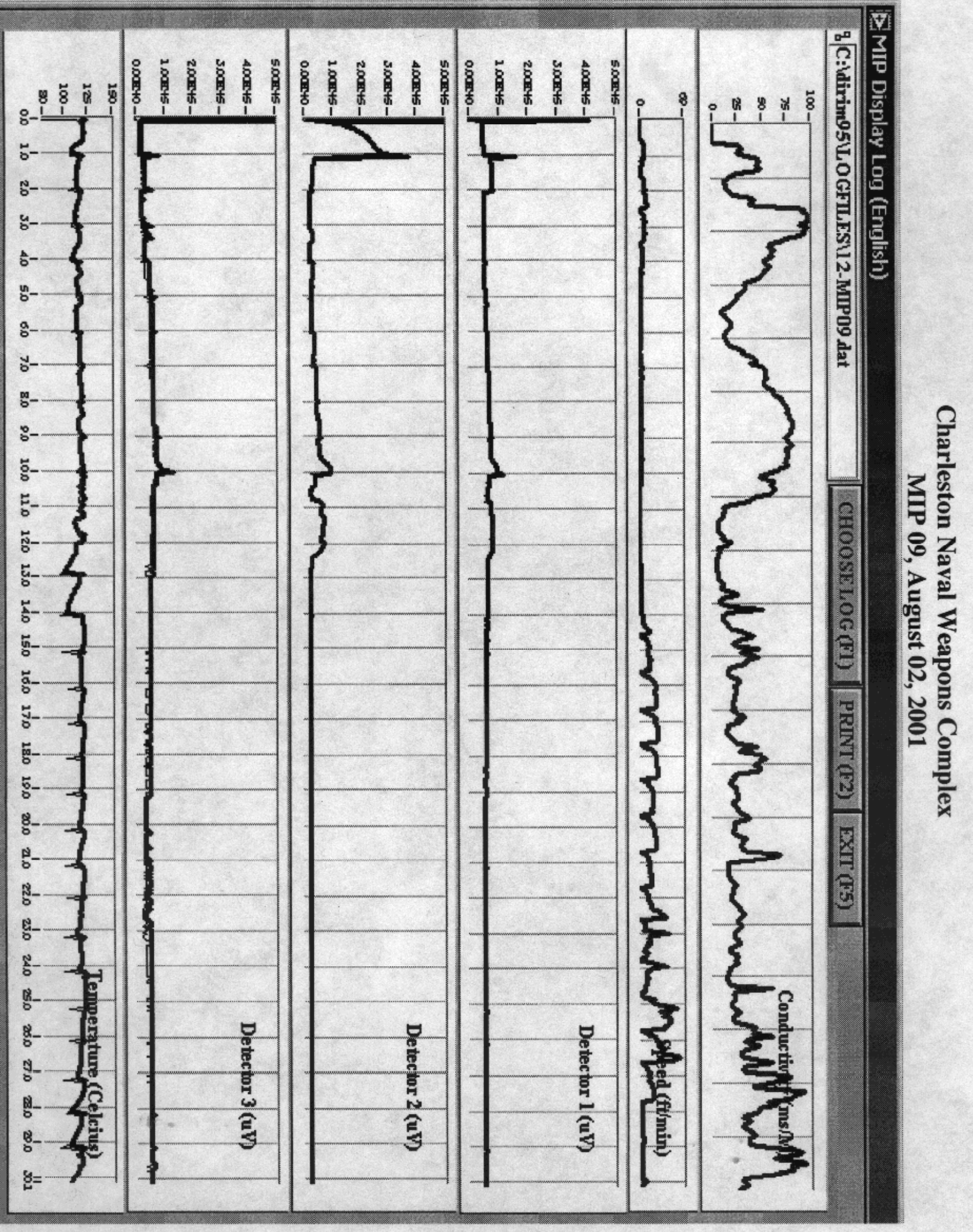




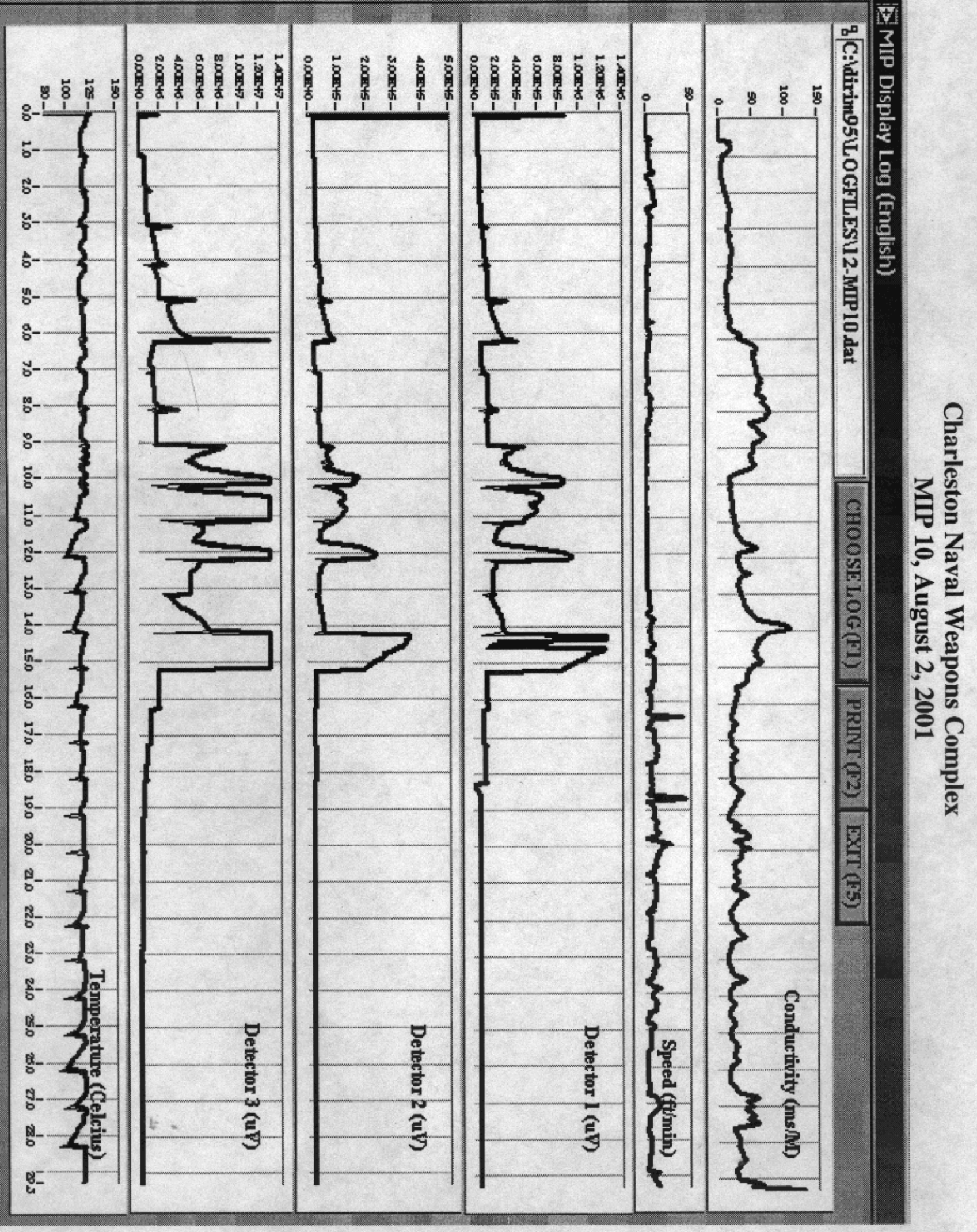




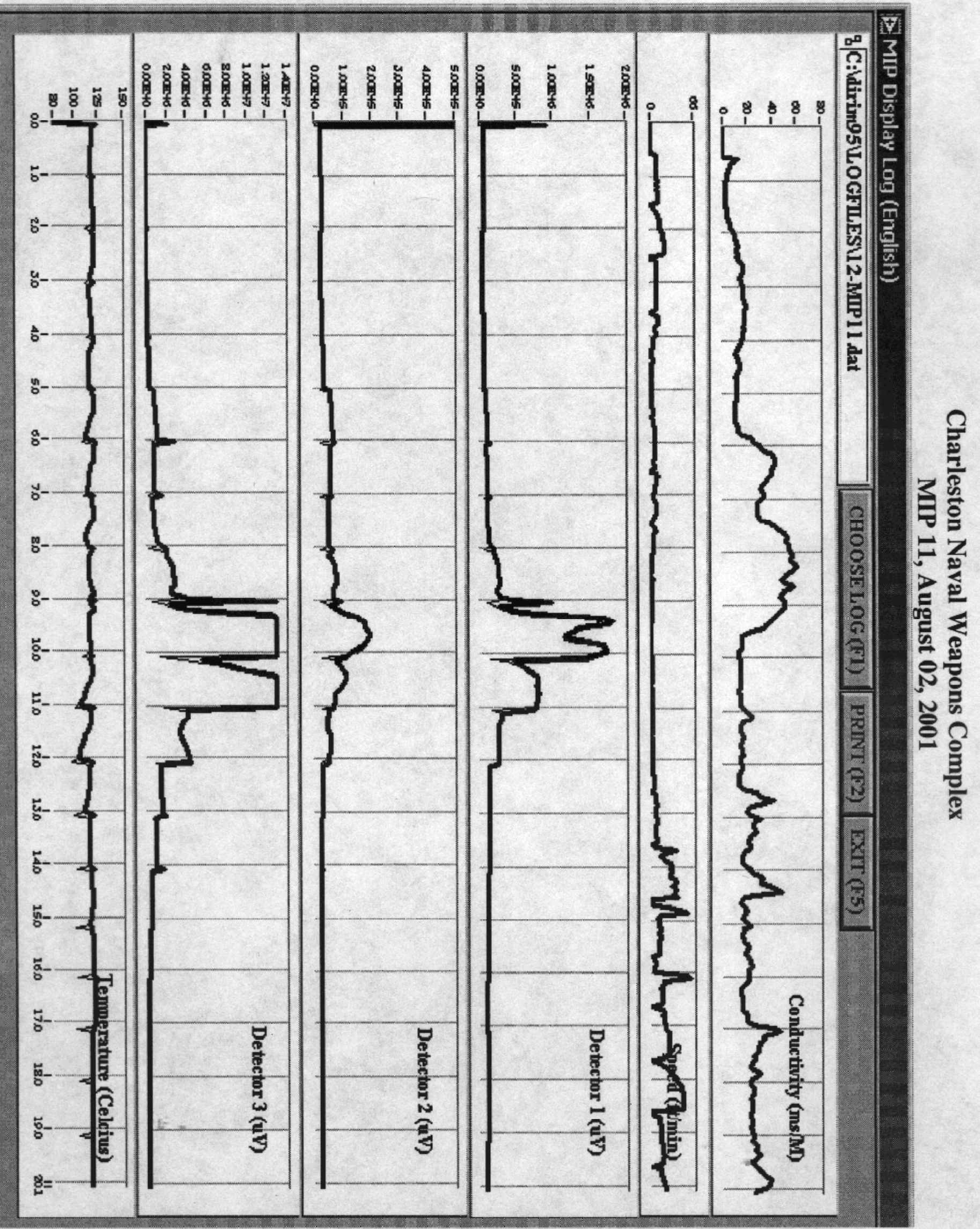




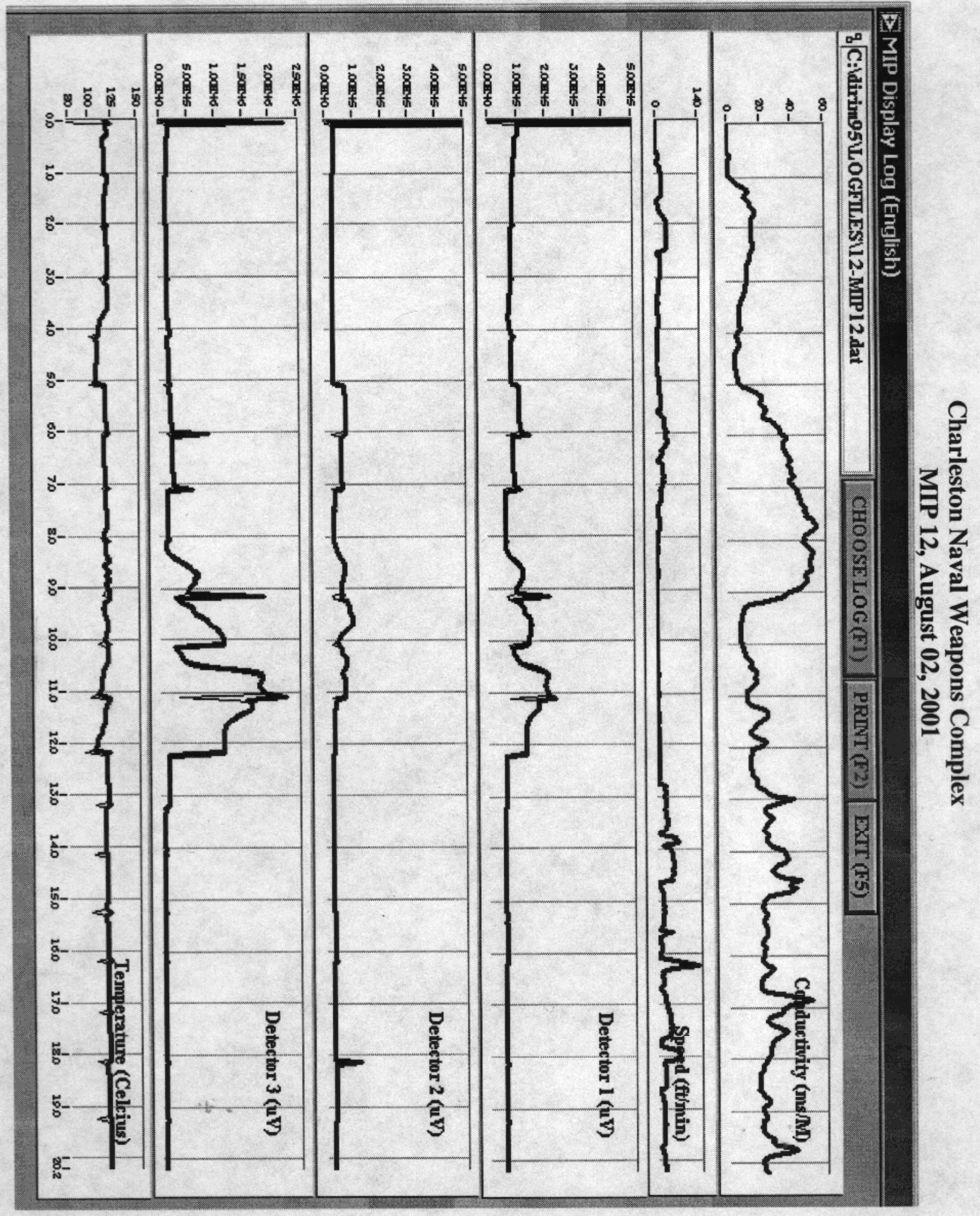




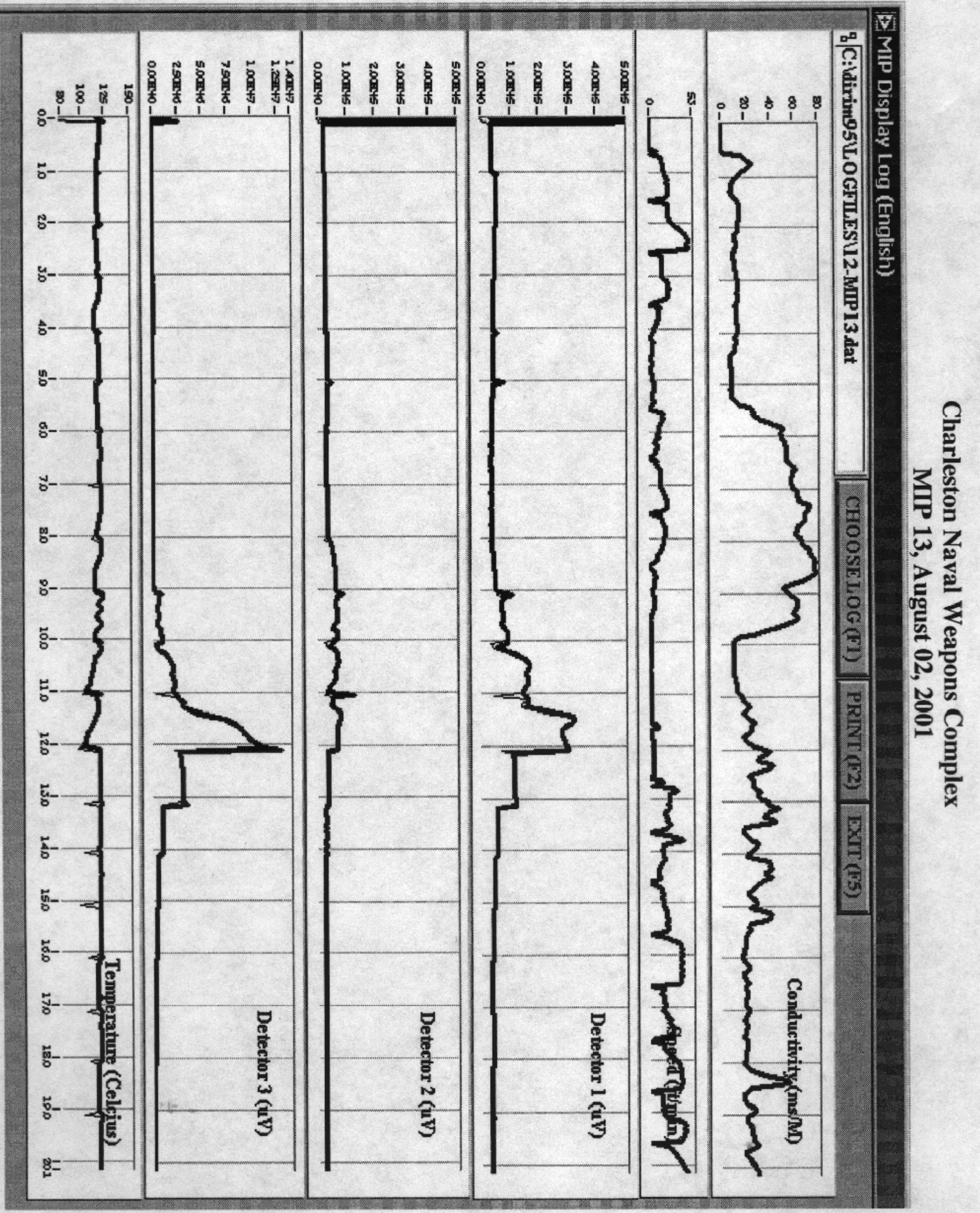




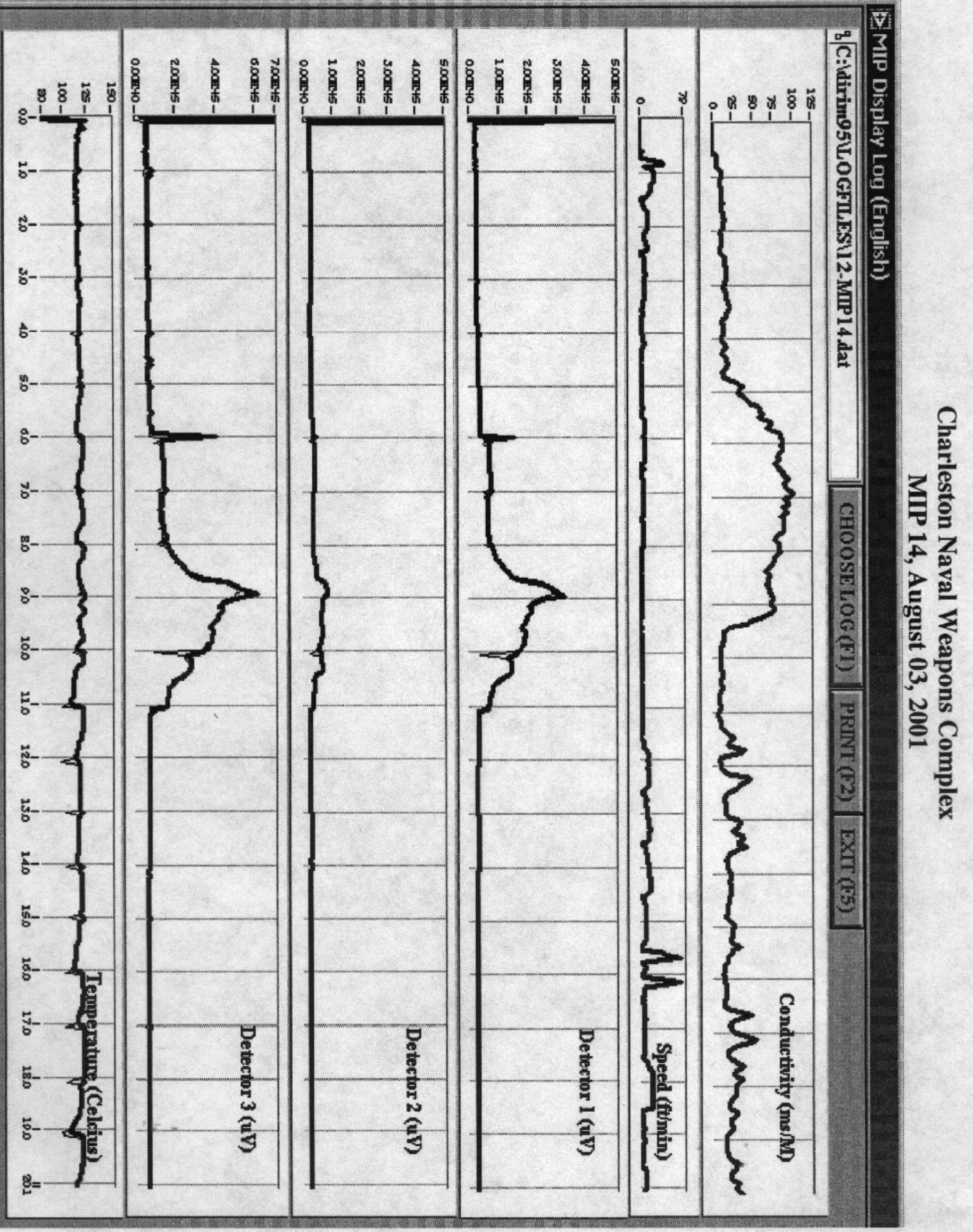




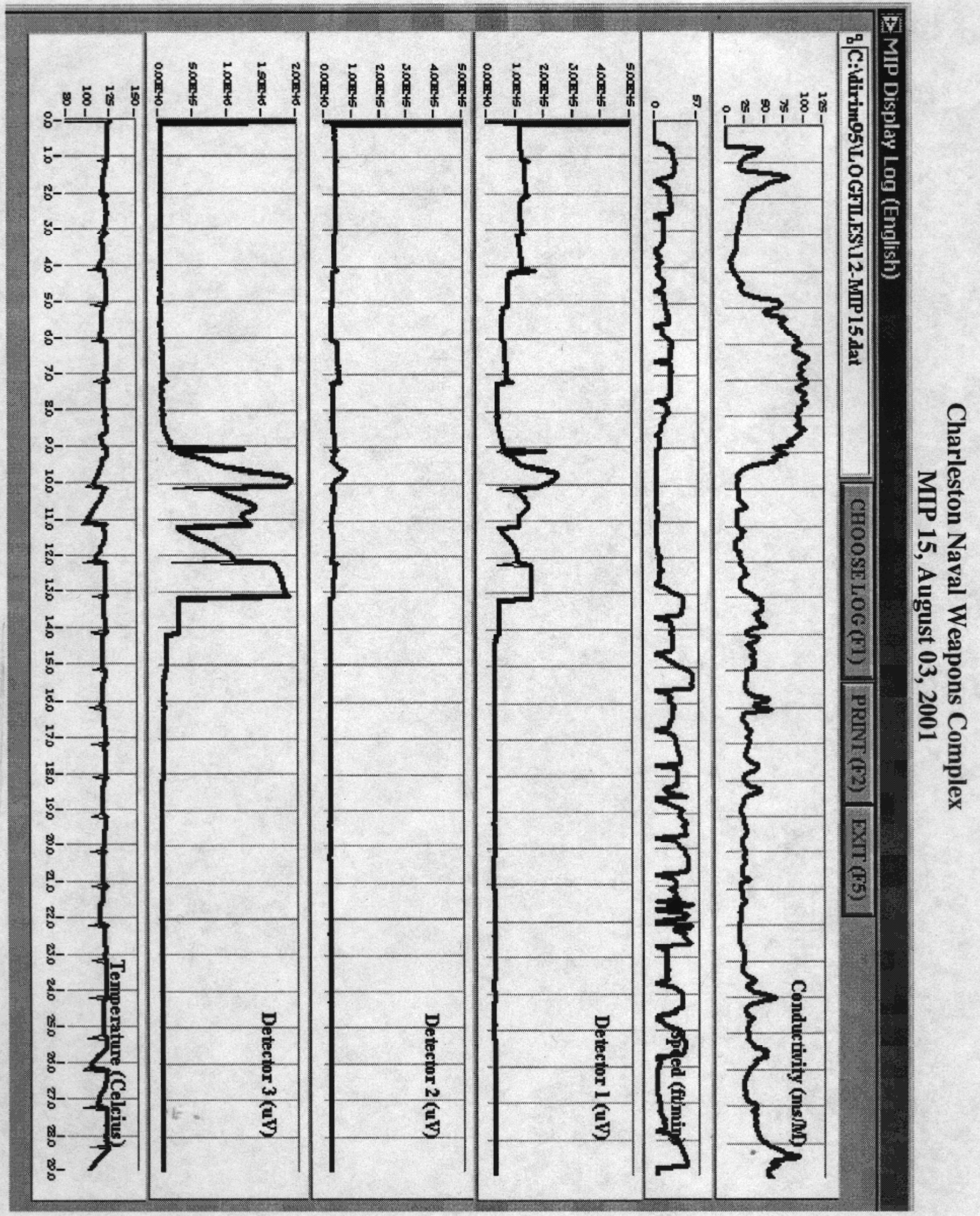




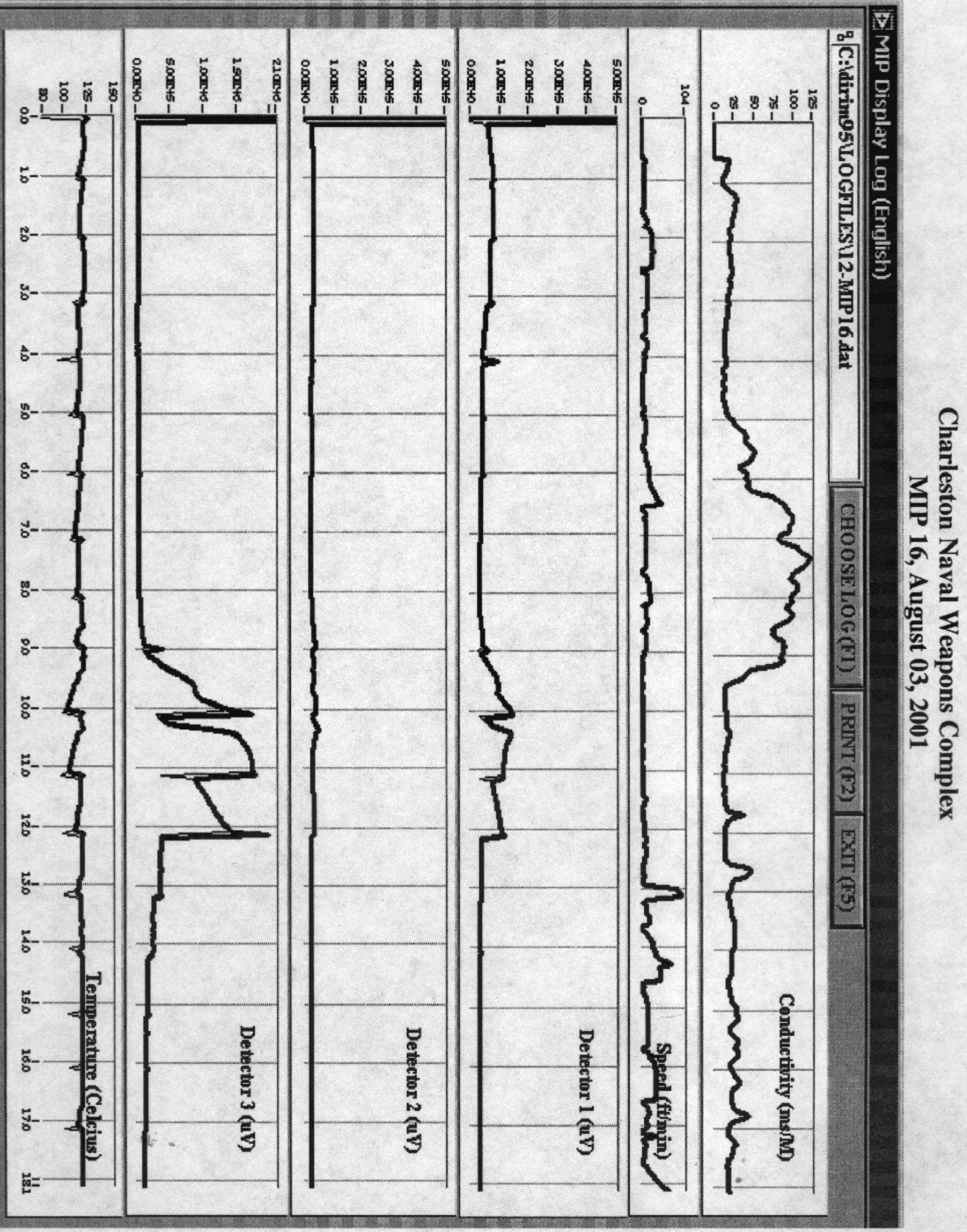




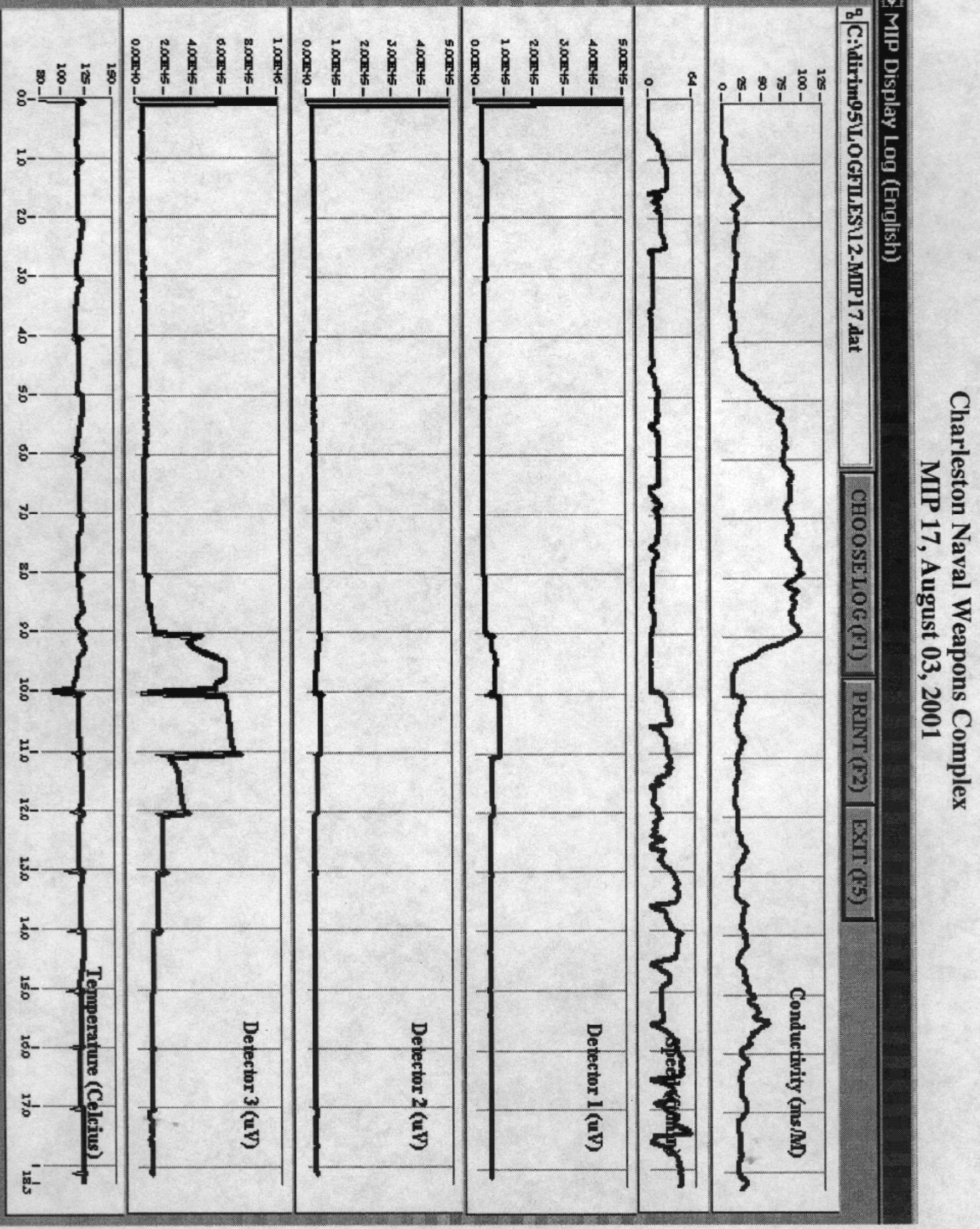




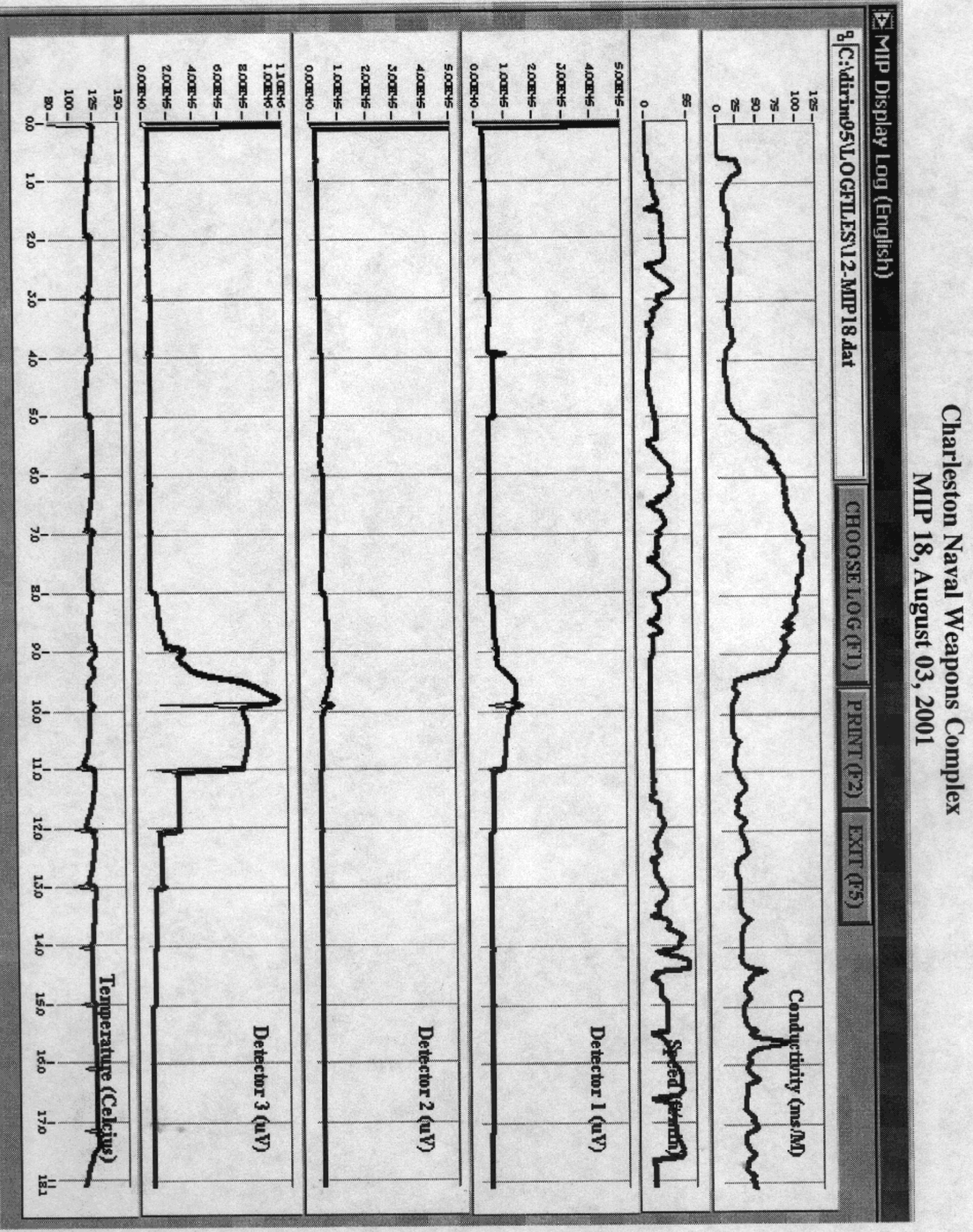




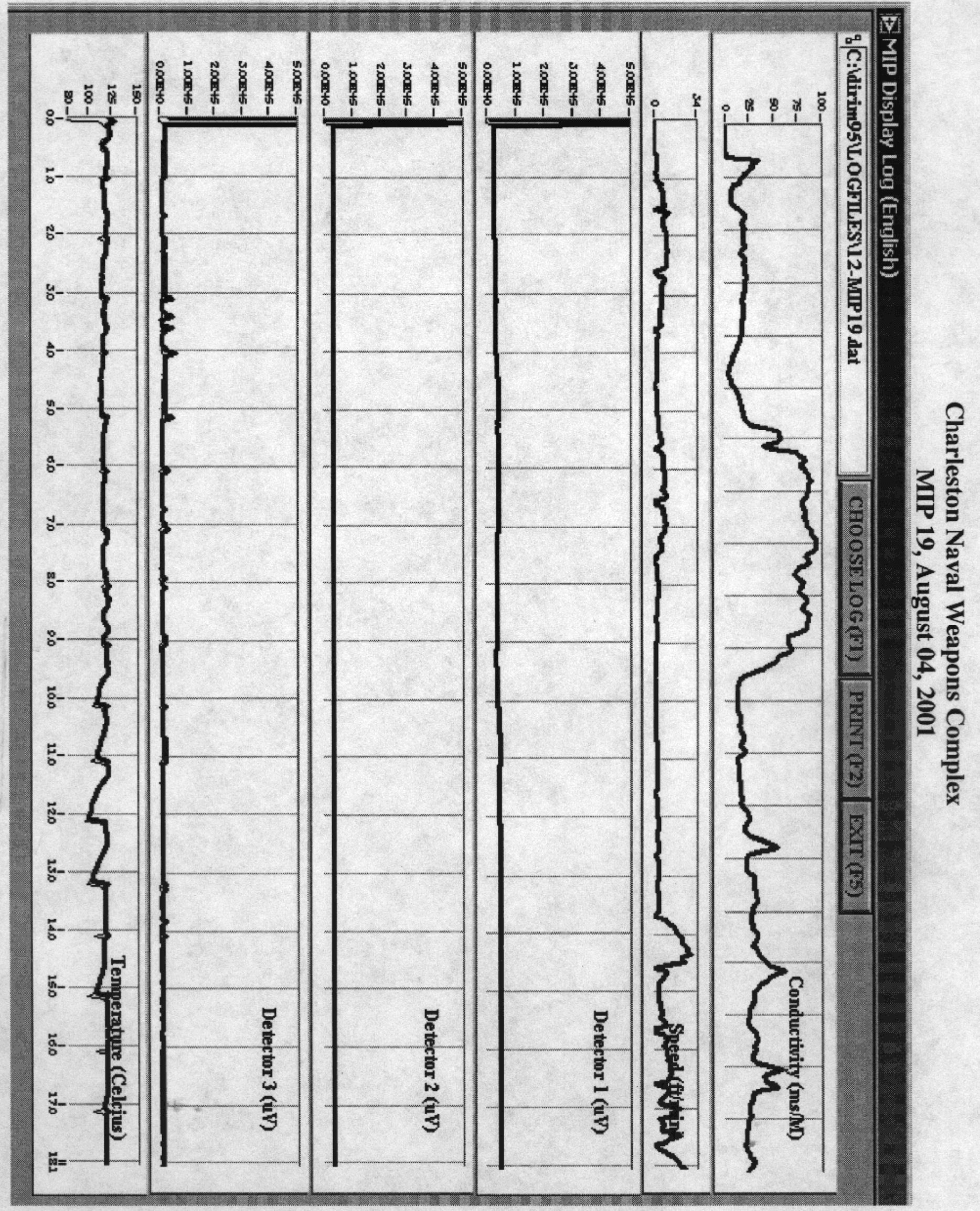




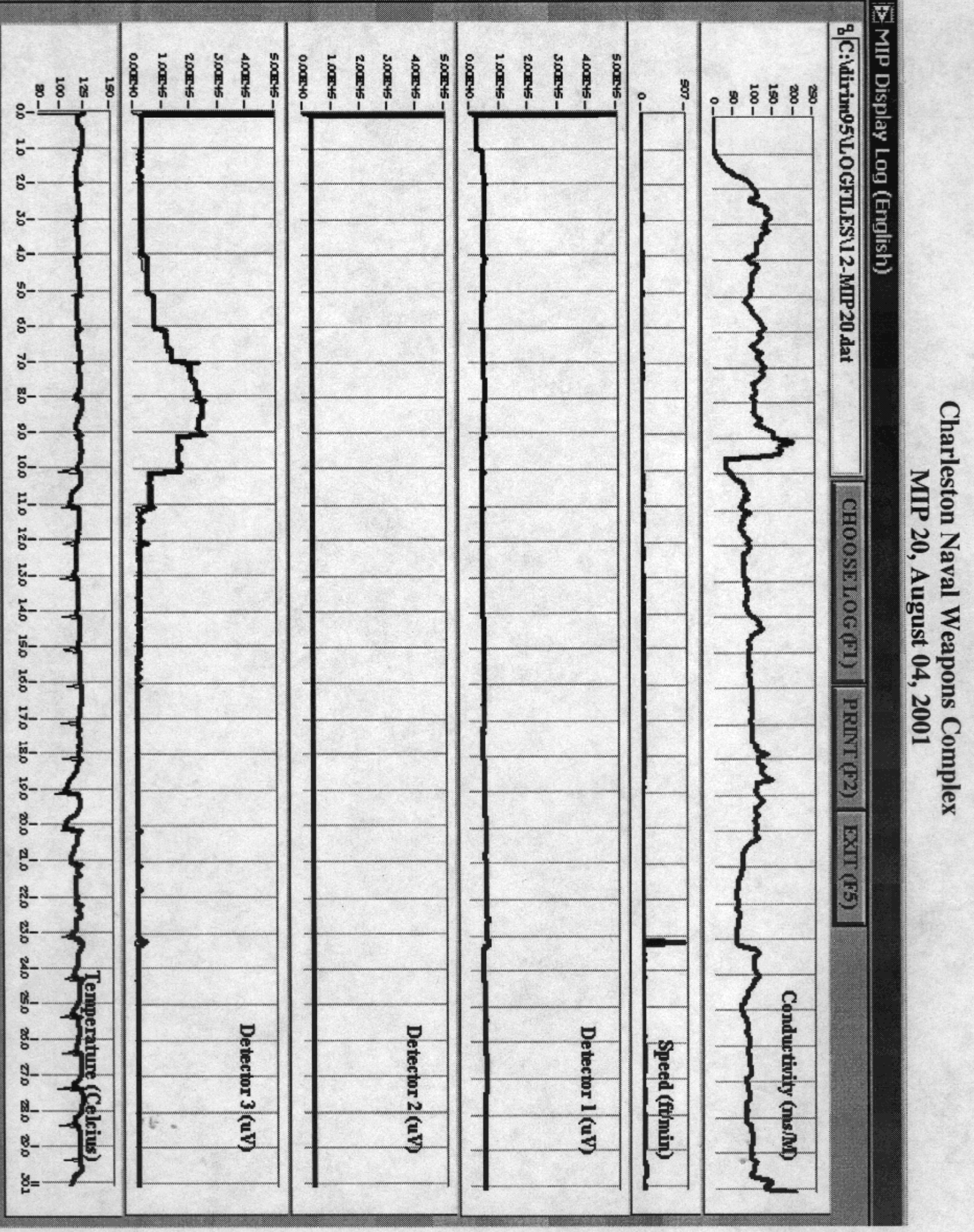

